\title{
Evaluation of the Met Office global forecast model using Geostationary Earth Radiation Budget (GERB) data
}

Article

Published Version

Allan, R. P., Slingo, A., Milton, S. F. and Brooks, M. E. (2007) Evaluation of the Met Office global forecast model using Geostationary Earth Radiation Budget (GERB) data. Quarterly Journal of the Royal Meteorological Society, 133 (629). pp. 1993-2010. ISSN 1477-870X doi:

https://doi.org/10.1002/qj.166 Available at https://centaur.reading.ac.uk/866/

It is advisable to refer to the publisher's version if you intend to cite from the work. See Guidance on citing.

Published version at: http://www3.interscience.wiley.com/journal/113388514/home

To link to this article DOI: http://dx.doi.org/10.1002/qj.166

Publisher: Royal Meteorological Society

All outputs in CentAUR are protected by Intellectual Property Rights law, including copyright law. Copyright and IPR is retained by the creators or other copyright holders. Terms and conditions for use of this material are defined in the End User Agreement. 


\section{CentAUR}

Central Archive at the University of Reading

Reading's research outputs online 


\title{
Evaluation of the Met Office global forecast model using Geostationary Earth Radiation Budget (GERB) data ${ }^{\dagger}$
}

\author{
Richard P. Allan, ${ }^{\mathrm{a} *}$ Anthony Slingo, ${ }^{\mathrm{a}}$ Sean F. Milton ${ }^{\mathrm{b}}$ and Malcolm E. Brooks ${ }^{\mathrm{b}}$ \\ a Environmental Systems Science Centre, University of Reading, Reading, UK \\ b Met Office, Exeter, UK
}

\begin{abstract}
Simulations of the top-of-atmosphere radiative-energy budget from the Met Office global numerical weatherprediction model are evaluated using new data from the Geostationary Earth Radiation Budget (GERB) instrument on board the Meteosat-8 satellite. Systematic discrepancies between the model simulations and GERB measurements greater than $20 \mathrm{Wm}^{-2}$ in outgoing long-wave radiation (OLR) and greater than $60 \mathrm{Wm}^{-2}$ in reflected short-wave radiation (RSR) are identified over the period April-September 2006 using 12 UTC data. Convective cloud over equatorial Africa is spatially less organized and less reflective than in the GERB data. This bias depends strongly on convective-cloud cover, which is highly sensitive to changes in the model convective parametrization. Underestimates in model OLR over the Gulf of Guinea coincide with unrealistic southerly cloud outflow from convective centres to the north. Large overestimates in model RSR over the subtropical ocean, greater than $50 \mathrm{Wm}^{-2}$ at $12 \mathrm{UTC}$, are explained by unrealistic radiative properties of low-level cloud relating to overestimation of cloud liquid water compared with independent satellite measurements. The results of this analysis contribute to the development and improvement of parametrizations in the global forecast model. Copyright (C) 2007 Royal Meteorological Society
\end{abstract}

KEY WORDS radiative processes; numerical weather prediction; cloud; aerosol; satellite data

Received 2 April 2007; Revised 1 August 2007; Accepted 31 August 2007

\section{Introduction}

Satellite observations of the Earth's radiation budget are used extensively in studies of climate forcing and variability, as well as in the evaluation of climate models (e.g. Martin et al., 2006). These data provide a direct measure of the energy streams associated with the absorption and reflection of solar radiation, and of the emission of thermal radiation to space, integrated over the spectrum. The presence of clouds may be identified; this enables a separation of the effects of changes in temperatures, humidities and clouds on the radiation streams and the potential for measuring the feedbacks associated with these changes in response to natural forcings (e.g. Soden et al., 2002).

In contrast to the extensive use of radiation-budget data in climate analysis and modelling, such data are employed much less frequently in numerical weather prediction (NWP). This is in part because the very attribute that makes the data attractive for climate

\footnotetext{
* Correspondence to: Richard P. Allan, Environmental Systems Science Centre, Harry Pitt Building, University of Reading, Reading, Berkshire, RG6 6AL, UK. E-mail: rpa@mail.nerc-essc.ac.uk

$\dagger$ The contributions of Sean Milton and Malcolm Brooks of Met Office, Exeter, were prepared as part of their official duties as employees of the UK Government. They are published with the permission of the Controller of Her Majesty's Stationery Office and the Queen's Printer for Scotland.
}

studies - namely, the spectrally-integrated nature of the broadband fluxes - makes them less useful for initializing NWP models, for which observations in much narrower spectral regions are preferred, since these provide specific information about, for example, the vertical profiles of temperature and humidity. Nevertheless, the data provide valuable diagnostic information for evaluating analyses and forecasts, independently of the data used in the initialization of the model. Geostationary data, with their high temporal resolution and coverage of large areas of the globe at one time, are particularly appropriate for this purpose.

Simulations of the top-of-atmosphere radiation budget from the Met Office global NWP model have routinely been compared with observations from the Geostationary Earth Radiation Budget (GERB) instrument (Harries et al., 2005) since May 2003 (Allan et al., 2005). As well as contributing to data validation (Harries et al., 2005; Allan et al., 2005), the methodology has been successfully applied in the examination of radiative processes (Haywood et al., 2005; Comer et al., 2007) and in model evaluation and development (Milton et al., 2005; Allan et al., 2006). In the present study, we extend previous analysis by using the release-version GERB data to evaluate the current version of the NWP model, concentrating in particular on the period April-September 2006. 
Table I. Operational changes to the NWP model. (The 'N216' notation refers to the number of two-grid-length waves that can be resolved (in this case 216), or half the number of grid points along a line of latitude. IGBP is the International Geosphere-Biosphere Programme: www.igbp.kva.se.).

\begin{tabular}{|c|c|c|}
\hline Cycle & Date & Details \\
\hline G32 & 26 May 2004 & $\begin{array}{l}\text { Improved use of satellite data, including high-resolution } \\
\text { spectral infrared sounder data (AIRS). }\end{array}$ \\
\hline G33 & 5 Oct 2004 & 3D-Var replaced by 4D-Var (Rawlins et al., 2007). \\
\hline G34 & 18 Jan 2005 & $\begin{array}{l}\text { HadGEM1 physics changes (Milton et al., 2005): } \\
\text { improvements to boundary layer and microphysics; increased } \\
\text { albedo over Sahara. }\end{array}$ \\
\hline G37 & 17 Aug 2005 & $\begin{array}{l}\text { Soil moisture nudging implemented. Introduction of NOAA-18 } \\
\text { and withdrawal of Aqua AMSU. }\end{array}$ \\
\hline G38 & 13 Dec 2005 & $\begin{array}{l}\text { Resolution enhancement: N216 L38 to N320 L50. Change in } \\
\text { model time step: } 20 \text { min to } 15 \mathrm{~min} .\end{array}$ \\
\hline G39 & 14 Mar 2006 & $\begin{array}{l}\text { Adaptive detrainment (Maidens and Derbyshire, 2007); } \\
\text { marine-boundary-layer improvements (Edwards, 2007). Met- } 7 \\
\text { sat-winds replaced by Met- } 8 \text { in the assimilation. }\end{array}$ \\
\hline G40 & 14 Jun 2006 & $\begin{array}{l}\text { Improved soil-moisture nudging to better account for soil } \\
\text { moisture contents below the wilting point; data-assimilation } \\
\text { upgrade and boundary-layer bug fixes. }\end{array}$ \\
\hline G41 & 26 Sep 2006 & $\begin{array}{l}\text { Wilson-Henderson-Sellers dataset replaced by IGBP } \\
\text { vegetation. Surface roughness modified; further improvements } \\
\text { to soil-moisture nudging; SSM/I and GPS radio occultation } \\
\text { introduced. }\end{array}$ \\
\hline G42 & 5 Dec 2006 & $\begin{array}{l}\text { Decay time-scale adopted for diagnosed convective-cloud } \\
\text { fraction. }\end{array}$ \\
\hline
\end{tabular}

\section{Model and data description}

\subsection{Global forecast model}

Over the period of study discussed, the Met Office global NWP model has undergone a number of operational changes to data assimilation, use of observations, and model formulation (resolution, physical parametrizations, and numerics). From May 2003 to May 2004 the model formulation was that of cycle G27, described in Allan et al. (2005). Table I lists the operational changes that have been made since then.

The latest version of the model has an additional 12 levels in the stratosphere, and the model lid raised to $65 \mathrm{~km}$ (cycle G38). This improved use of satellite data in the assimilation gives a closer fit of the model to the observations, and an improved analysis. The horizontal resolution has been increased from a grid of $0.833^{\circ}$ longitude by $0.556^{\circ}$ latitude (about $60 \mathrm{~km}$ in mid-latitudes) to $0.5625^{\circ}$ longitude by $0.375^{\circ}$ latitude (about $40 \mathrm{~km}$ in mid-latitudes). The NWP model physical formulation at cycle G34 is very similar to that employed in the HadGEM1 version of the climate model (Martin et al., 2006), and since then the NWP and climate models have developed together (for example, both have physics changes at cycle G39). This gives us confidence that the deficiencies highlighted in the NWP model by comparisons with GERB will prove useful for climatemodel development. This is further supported by recent work showing that the NWP and climate versions of the model display very similar cloud regimes (Williams and Brooks, 2007).
The impact of some of these improvements can be identified in changes in the model radiative forcing compared to GERB. These are discussed in detail in the following sections.

\subsection{Satellite and ancillary data}

Edition 1 averaged, rectified, geolocated level 2 broadband radiative-flux data from the GERB (Harries et al., 2005) instrument are employed, considering in detail the period April-September 2006. The absolute accuracy is estimated at $2.25 \%$ for solar radiance and $0.96 \%$ for thermal radiance. Broad-band radiative fluxes are derived from the unfiltered measured radiance using angulardependence models, which are likely to incur additional uncertainty of order $5 \mathrm{Wm}^{-2}$ for thermal fluxes and $10 \mathrm{Wm}^{-2}$ for typical solar fluxes (Harries et al., 2005; Loeb et al., 2007). Higher errors may be present for aerosol and for high thin cloud (Jacqui Russell, personal communication). The temporal resolution is approximately $17 \mathrm{~min}$; we use the data that most closely match the model output times.

In addition to the flux products, a cloud-fraction product, generated as part of the GERB processing, is used in the analysis. This was developed at the Royal Meteorological Institute of Belgium (RMIB) by Ipe et al. (2004), and is based on short-wave channels from the Spinning Enhanced Visible and Infrared Imager (SEVIRI), also on board the Meteosat-8 satellite (Schmetz et al., 2002). Also based on SEVIRI data is the Meteorological Product Extraction Facility (MPEF) cloud mask, which is available night and day. 
We also utilize $0.55 \mu \mathrm{m}$ aerosol-optical-depth data from the Multi-Angle Imaging Spectroradiometer (MISR) version AM1_CGAS_F06_0021 (Diner et al., 2001), cloud-liquid-water (CLW) data from the Special Sensor Microwave Imager (SSM/I) version 6 (Wentz, 1997), and vertical-velocity fields from the NCEP/NCAR 40-year reanalysis (Kalnay et al., 1996). Additionally, CloudSat (Stephens et al., 2002) cloud-mask data (2B-GEOPROF version R03) were utilized in comparisons of model vertical cloud structure. We use the Cloud Precipitation Radar (CPR) cloud-mask product, and assume values of 20-40 to be cloud detections, while weak-detection values of 5-10 are assumed to correspond to clear skies.

\subsection{Methodology and definitions}

We use the methodology described in Allan et al. (2005) to generate model fluxes and additional diagnostics at the model analysis times (commencing at 00, 06, 12 and 18 UTC) for the duration of the model time step (15 min or $20 \mathrm{~min}$ - see Table I). Additionally, $3 \mathrm{~h}$ forecasts run from the model analysis times are used to generate a further four sets of model output times at 03, 09, 15 and 21 UTC for some of the period considered. A three-hourly archive of model and GERB-SEVIRI comparisons is subsequently generated. The GERB and model data are interpolated onto a regular grid of resolution $0.833^{\circ}$ longitude by $0.556^{\circ}$ latitude. This is the resolution of the NWP model prior to December 2005; thereafter the model resolution was increased to $0.5625^{\circ}$ longitude by $0.375^{\circ}$ latitude (Table I). Unless stated otherwise, all analysis is conducted using the lower-resolution interpolated model data. This ensures that both the model and the GERB data undergo an interpolation step in the processing, as well as allowing backward-compatibility with an earlier version of the NWP model.

The outgoing long-wave radiation (OLR) and reflected short-wave radiation (RSR) at the top of the atmosphere are simulated by the model and compared with the corresponding quantities from GERB. Additionally, the incoming solar radiation (ISR) at the top of the atmosphere is calculated, in a manner consistent with the model parametrization, for the exact time of the GERB RSR observations, as described in Allan et al. (2005). Short-wave albedo $(\alpha)$ is calculated as the proportion of ISR that is reflected back to space as RSR. This helps to reduce RSR differences due to the temporal mismatch between the GERB and model time steps.

Cloud fraction $\left(A_{\mathrm{c}}\right)$ is an additional diagnostic generated by the model and in the processing of the GERB data ('IPE') and SEVIRI data ('MPEF'). These are used to generate consistently-sampled clear-sky diagnostics from the model and GERB. These diagnostics (type I) only sample coincident cloud-free pixels. Unless stated otherwise, type I clear-sky fluxes are used in comparisons between GERB and the model. In addition to the type I diagnostics, clear-sky fluxes are also generated within the model by setting cloud fraction to zero (type II), as described in Allan et al. (2005). These are used to estimate the effect of cloud on the radiative fluxes by subtracting the model type II clear-sky radiation. Type I diagnostics cannot easily be applied in this case since there are no observations of clear-sky fluxes during overcast conditions. The long-wave cloud radiative forcing (LWCF) is calculated as:

$$
\begin{aligned}
L W C F_{\text {gerb }} & =O L R c_{\mathrm{m}}-O L R_{\text {gerb }} \\
L W C F_{\mathrm{m}} & =O L R c_{\mathrm{m}}-O L R_{\mathrm{m}}
\end{aligned}
$$

where $O L R c_{\mathrm{m}}$ is the model-simulated type II clear-sky OLR, and the subscripts ' $\mathrm{m}$ ' and 'gerb' refer to model fields and GERB observations respectively. The albedo cloud forcing (ALBCF) is calculated as:

$$
\begin{aligned}
A L B C F_{\text {gerb }} & =\alpha_{\text {gerb }}-\alpha_{\mathrm{c} \_\mathrm{m}} \\
A L B C F_{\mathrm{m}} & =\alpha_{\mathrm{m}}-\alpha_{\mathrm{c} \_\mathrm{m}}
\end{aligned}
$$

where $\alpha_{\mathrm{c} \_m}$ is the model-simulated type II clear-sky albedo. The analysis of Allan et al. (2005) suggested that simulated clear-sky fluxes over the ocean agreed with coincident preliminary GERB data to within $5-10 \mathrm{Wm}^{-2}$ for clear-sky OLR and to within 0.01 for short-wave albedo. The GERB-calculated LWCF and ALBCF are also limited by these errors.

\section{Global comparison for 12 UTC data}

Composites of the consistently-sampled model-minusGERB differences in OLR and RSR over the period April-September 2006 were generated using 12 UTC data (Figure 1). Also shown are the clear-sky composites using only pixels for which both the model and the satellite data indicated cloud cover below $1 \%$, the modelminus-IPE cloud-cover differences, and the model bias in net downward radiation at the top of the atmosphere. The model RSR was calculated as $\alpha_{\mathrm{m}} \times I S R_{\text {gerb }}$, to account for the slight differences in solar time between the simulations and the measurements.

Differences in OLR over much of the oceans are generally within about $5 \mathrm{Wm}^{-2}$, suggesting that systematic model errors in mean temperature and humidity and upper-level clouds are relatively small. Larger differences occur at the southern and eastern limbs. An OLR discrepancy of order $10 \mathrm{Wm}^{-2}$ over parts of the subtropical and mid-latitude Atlantic is also present when only clear-sky scenes are sampled.

There are model-minus-GERB differences substantially greater than the expected uncertainty in the satellite data. Over Europe, the model overestimates OLR by $10-20 \mathrm{Wm}^{-2}$ and underestimates RSR by over $50 \mathrm{Wm}^{-2}$. This signal is not present in the clear-sky cases, or at other model analysis times, and is consistent with a $20 \%$ underestimation in simulated cloud cover at midday (Figure 1(c)).

The North African region $\left(10^{\circ}-40^{\circ} \mathrm{W}, 10^{\circ}-30^{\circ} \mathrm{N}\right)$ is characterized by overestimates in Saharan OLR and 
(a) Model-GERB OLR

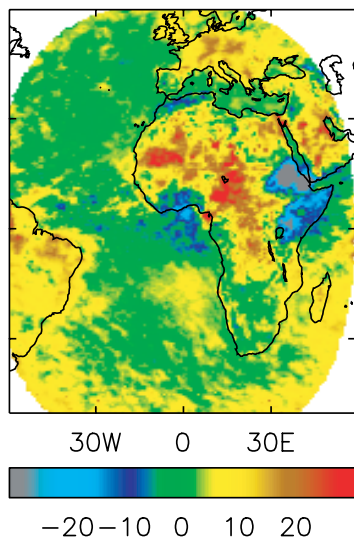

(d)

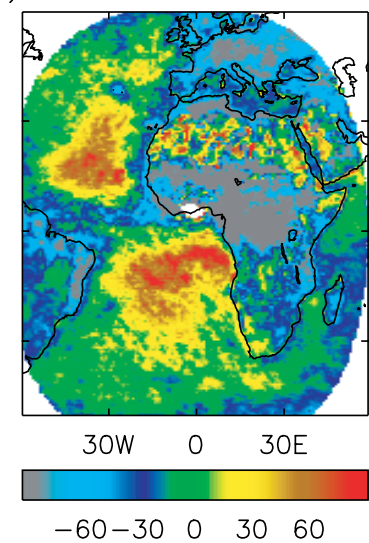

(b) Model-GERB OLRC

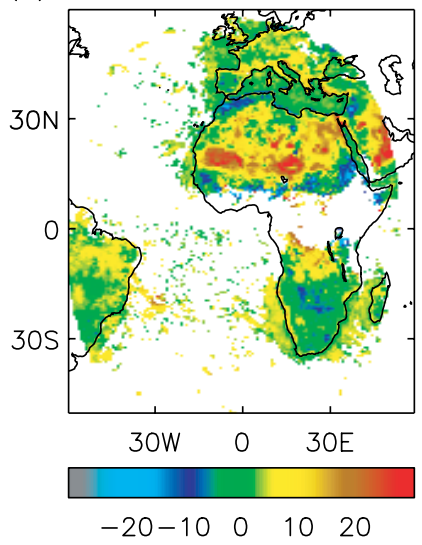

(e) Model-GERB RSRc

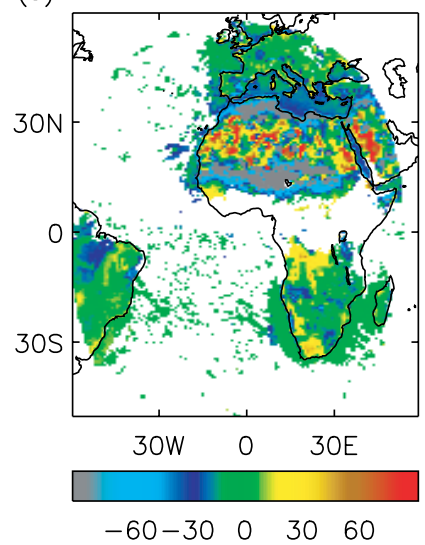

(c) Model-IPE Cloud

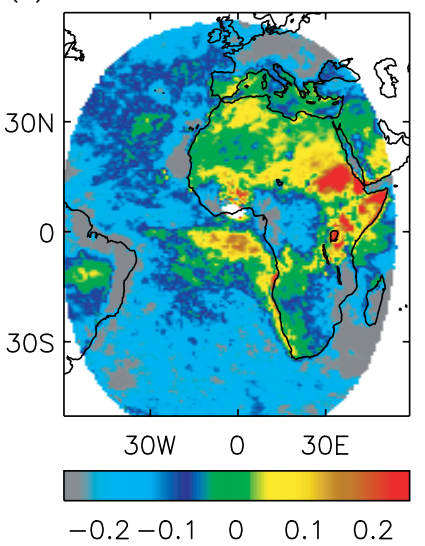

(f) Model-GERB NET

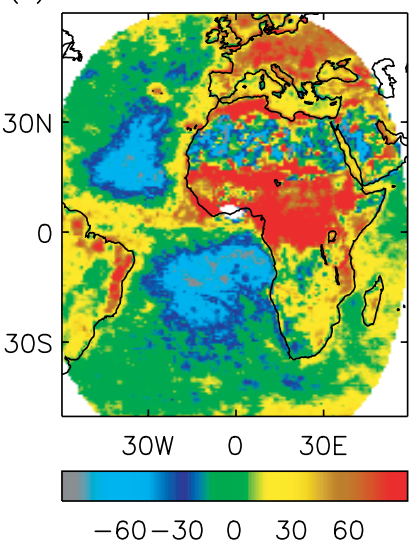

Figure 1. Model-minus-GERB differences in radiative fluxes and cloud for 12 UTC data over the period April-September 2006: (a) OLR; (b) clear-sky OLR; (c) cloud fraction; (d) RSR; (e) clear-sky RSR; (f) net short-wave and long-wave downward top-of-atmosphere radiation. White areas indicate missing data; there are more missing data for the clear-sky comparisons because many regions lack coincident cloud-free comparisons during the period of study.

underestimates in RSR over the sub-Saharan regions, including the Sahel and the northern coast of Africa. These signals originate from the clear-sky scenes, and in the case of the long-wave radiation are present also for 15 and 18 UTC, but less so for 06 UTC. While some of the discrepancy relates to an unrealistic surface emissivity, which is set to unity in the model, previous analysis suggests that much of the signal can be explained by high mineral-dust optical depths that are not represented by the model (Haywood et al., 2005). Indeed, for July 2006 , there is a spatial correlation coefficient of 0.66 between model-minus-GERB clear-sky OLR differences for 12-18 UTC data and $0.55 \mu \mathrm{m}$-aerosol optical depth from MISR (not shown). The reason for the peak in the dust radiative effect around 12-18 UTC is likely to be a combination of two factors: first, the difference between surface and atmospheric emitting temperatures is maximal around 12 UTC (e.g. Haywood et al., 2005); and secondly, the dust concentration and vertical extent is maximal around $18 \mathrm{UTC}$, relating to the evolution of the planetary boundary layer (e.g. Chaboureau et al., 2007). Work is currently under way to assess the Met Office model simulations over this region (Milton et al., 2007) and to develop seasonal climatologies of a variety of aerosol species, including mineral dust.
The clear-sky RSR differences over Africa are likely to relate to an unrealistic spatial distribution of surface albedo in the model. Preliminary comparisons of model surface albedo with an albedo climatology from the Moderate-Resolution Imaging Spectroradiometer (MODIS) instrument show a difference pattern similar to Figure 1(e) (not shown). This analysis will be presented elsewhere. Improved bare-soil albedos over desert regions based on MODIS data were implemented on 15 May 2007 (model cycle G44).

Over the Tropics, the model underestimates OLR over the north Ethiopian highlands $\left(40^{\circ} \mathrm{E}, 15^{\circ} \mathrm{N}\right)$ and the Gulf of Guinea $\left(0^{\circ} \mathrm{E}, 0^{\circ} \mathrm{N}\right)$, while overestimating OLR in the region of the Cameroon Highlands $\left(15^{\circ} \mathrm{E}, 10^{\circ} \mathrm{N}\right)$. These anomalies are not apparent in the clear-sky or shortwave comparisons, and this suggests that they relate to errors in higher-altitude cloud properties. There is indeed a large model overestimate in cloud fraction over the Ethiopian highlands, consistent with the OLR bias. At other model analysis times (not shown), the signals are also present, peaking over the Ethiopian highlands at 12 UTC, over Cameroon at $18 \mathrm{UTC}$, and over the Gulf of Guinea at 00-06 UTC. It is not clear whether these anomalies are linked. A substantial underestimation of model RSR (around $100 \mathrm{Wm}^{-2}$ ) is apparent over 
tropical convective regions of Africa, while the model overestimates RSR over the subtropical regions of the Atlantic $\left(0^{\circ} \mathrm{W}, 10^{\circ} \mathrm{S} ; 30^{\circ} \mathrm{W}, 20^{\circ} \mathrm{N}\right)$, up to a similar magnitude. This is despite cloud-fraction bias of variable sign. Errors in net downward radiation at the top of the atmosphere (Figure 1(f)) are similar but opposite in sign to the RSR differences, since the large insolation at this time of day dominates the radiation budget.

Time series of mean OLR and albedo over the GERB field of view at 12 UTC, and the model-minus-GERB differences, are shown for ocean (Figure 2) and land (Figure 3) regions. In addition to the Edition 1 GERB data (covering the period marked by a black bar across the top of the figures), these also include preliminary, pre-release GERB data, which are subject to varying processing and a different spectral response from the Edition 1 GERB data. For the Edition 1 period, in addition to physical changes in the radiative-energy balance, the time series are also affected by updates to the model (Table I).

The observed daily and seasonal variability in OLR is well captured by the model, with agreement to within about $5 \mathrm{Wm}^{-2}$ (Figure 2(a)). For much of 2006, GERB data exhibit a positive model-minus-GERB difference (Figure 2(c)); considering Figure 1(a), we see that this originates in part from the southern and eastern satellite viewing limbs, where the GERB data are most uncertain, but also from other areas such as the South Atlantic marine stratocumulus region. The mean bias, of about $3 \mathrm{Wm}^{-2}$, is similar to the absolute GERB accuracy of $1 \%$.

Variations in albedo over the oceans (Figure 2(b,d)) show large discrepancies. These relate to changes both in the processing of the preliminary GERB data prior to April 2004 and in model parametrizations. A change from negative model-minus-GERB albedo differences to very little bias after March 2006 relates primarily to improvements in the boundary-layer scheme (cycle G39 - see Table I). The April-September 2006 period shows excellent agreement between GERB and the model in the mean, although there exist compensating errors over the marine stratocumulus regions (positive modelminus-GERB differences) and the intertropical convergence zone (ITCZ) and southeastern limb (negative differences), as shown in Figure 1(d).

For land regions, OLR variation is larger over the seasonal cycle (Figure 3(a)), mainly because of the heating and cooling of the landmasses of the Northern Hemisphere. For ocean regions, the model simulates these variations well, but with a larger positive model-minus-GERB bias of around $5-10 \mathrm{Wm}^{-2}$ for the March-November 2006 period. This positive bias originates from a variety of regions, including equatorial

(a)

(b)

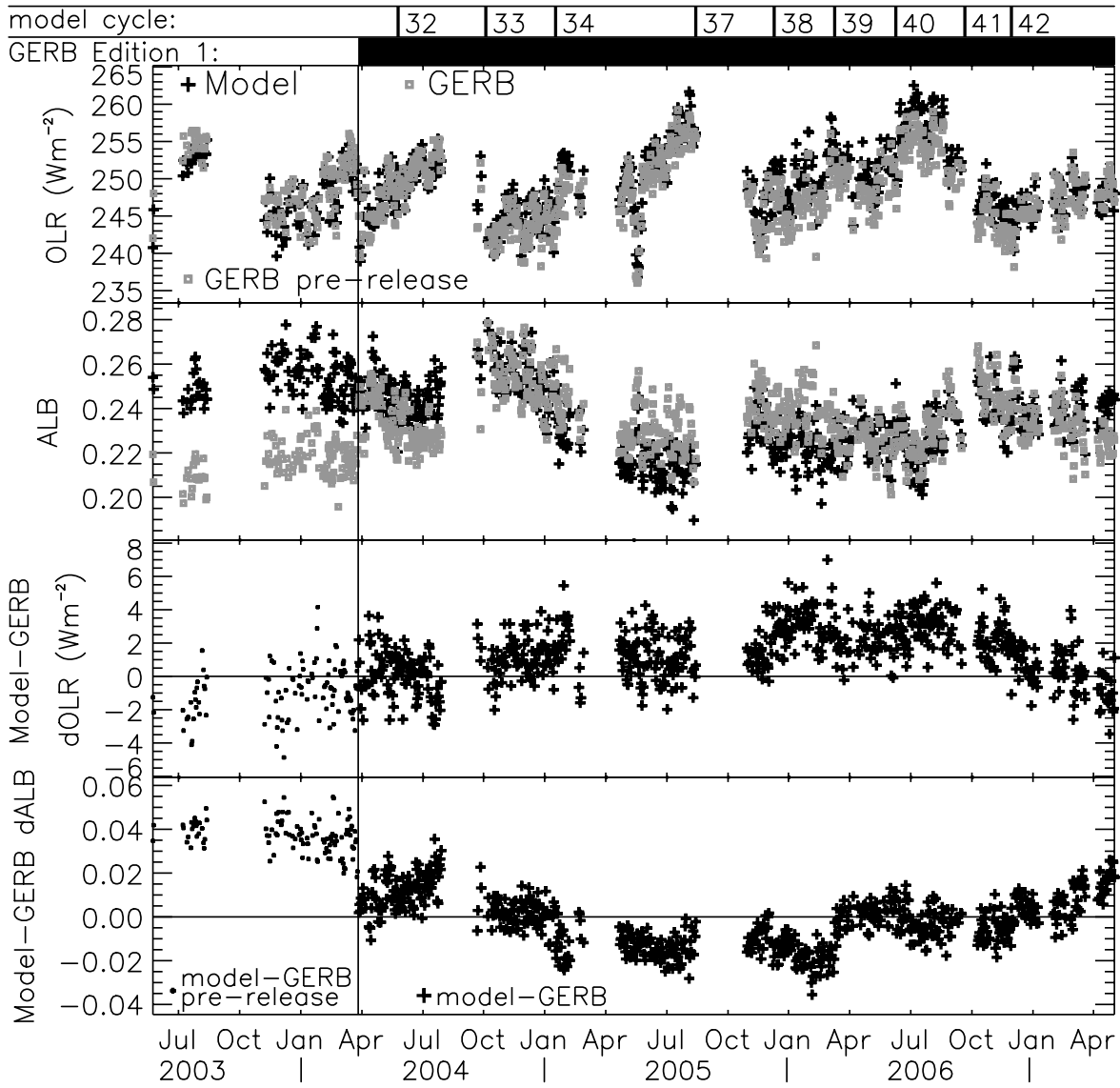

Figure 2. Time series of 12 UTC ocean-average radiative fluxes over the GERB field of view: (a) OLR; (b) short-wave albedo; (c) model-minus-GERB OLR difference; (d) model-minus-GERB short-wave albedo difference. The period after 27 March 2004 (indicated by vertical lines and black bar above) contains Edition 1 GERB data; before this, unvalidated pre-release GERB data are shown. The model cycle number is displayed at the top (see Table I for details). 


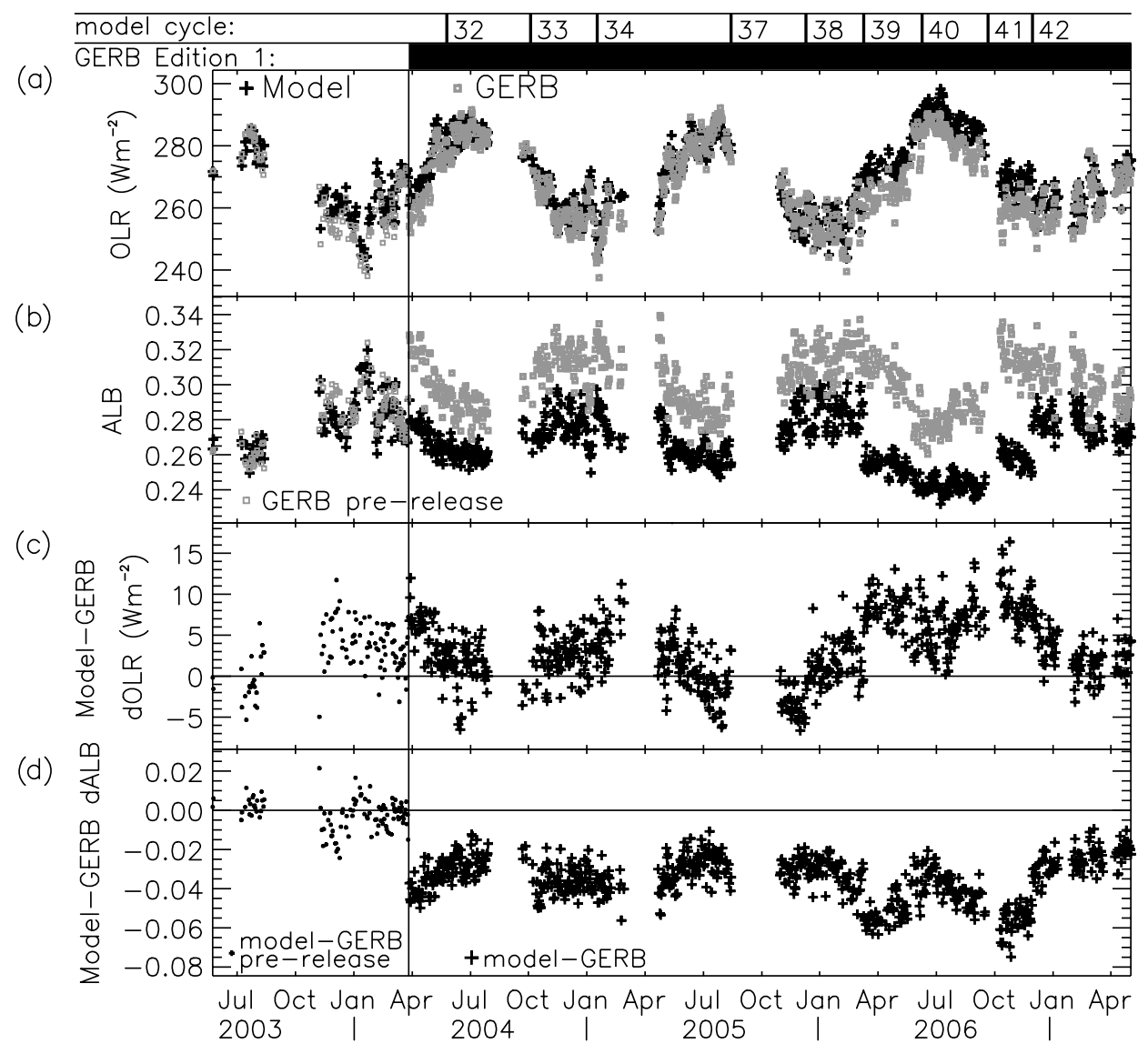

Figure 3. As Figure 2, but for land regions.

Africa and Europe, but also from the predominantly clear-sky North African and Saudi Arabian regions (around $20^{\circ} \mathrm{N}$ ); this may be explained by high mineraldust aerosol optical depth not represented in the model (Haywood et al., 2005).

In contrast to the ocean comparisons, the MarchNovember 2006 period displays a larger albedo and OLR bias than the rest of the time series, especially with respect to the pre-release GERB data, which are subject to substantially different processing and spectral response. However, a big drop in model short-wave albedo is also evident in March 2006, relating to model updates (cycle 39 - see Section 2.1), in particular a decreased convective cloud albedo over tropical Africa relating to the implementation of modified adaptive detrainment in the convection parametrization (Maidens and Derbyshire, 2007). This is clearly evident in Figure 1(d), which shows large negative model-minus-GERB RSR differences over tropical Africa. Also contributing to the area-mean bias for this period are underestimations in RSR over Europe for cloudy scenes and over the Sahel $\left(15^{\circ} \mathrm{N}\right)$ and North African coastal countries for clear-sky scenes.

In the period prior to the March 2006 model changes, the model-minus-GERB differences become more positive for OLR and more negative for albedo. This coincides with a period of drying soils following the implementation of a soil-moisture nudging scheme in August 2005. It is possible that this drying was exacerbated by the reduced convective-cloud albedo, so reducing the amount of cloud over land, thereby explaining the trends in the model radiative fluxes. Similarly, a reduction in negative model-minus-GERB albedo errors from April to June 2006 (Figure 3(d)) appears to be reversed following further changes to the soil-moisture nudging scheme on 14 June (Table I).

We now analyse in more detail the main discrepancies between model and GERB data, and relate these to cloudradiation processes, including convection over equatorial Africa, convectively-generated cloud over the Gulf of Guinea, and marine stratocumulus cloud over the South Atlantic.

\section{Convection across equatorial Africa}

Large model biases in OLR (around $30 \mathrm{Wm}^{-2}$ ) and RSR (around $100 \mathrm{Wm}^{-2}$ ) were identified over equatorial Africa using 12 UTC data from April-September 2006 (Figure 1). In this section we concentrate on the large underestimation in model short-wave albedo over continental Africa $\left(7^{\circ}-45^{\circ} \mathrm{E}, 10^{\circ} \mathrm{S}-10^{\circ} \mathrm{N}\right)$.

\subsection{Spatial structure and cloud radiative properties}

Figure 4 shows instantaneous model and GERB shortwave albedo fields for 12 UTC on 5 June 2006. Here we use the original (un-interpolated) model resolution to 
(a)

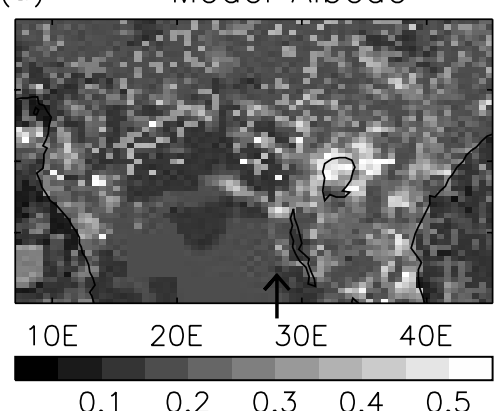

(b)

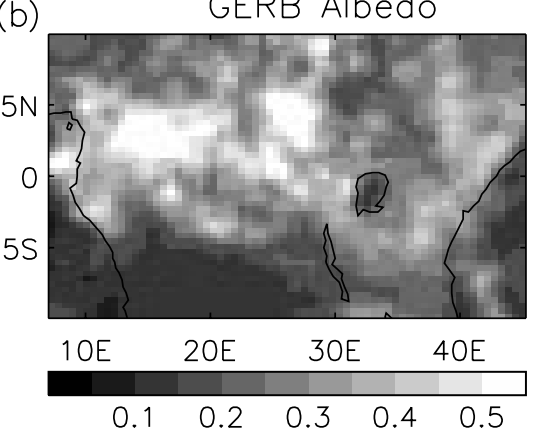

(c)

Model cloud fractions; $28^{\circ} \mathrm{E}$

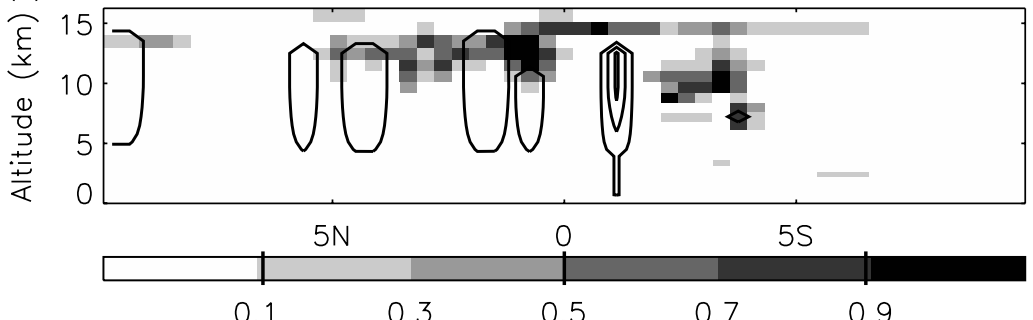

Figure 4. Short-wave albedo at 12 UTC on 5 June 2006 over equatorial Africa: (a) model data (original resolution); (b) GERB; (c) cross-section of model convective cloud (contours at $0.1,0.5$ and 0.9 ) and layer cloud (shading) at $28^{\circ} \mathrm{E}$ (shown by arrow in (a)).

highlight the structure of convection. The dark, cloudfree regions observed to the northwest and, more especially, to the southwest of the region are captured by the model. However, consistent with previous analysis (Allan et al., 2005), the convective cloud appears more spatially organized in the satellite data compared with the scattered, pixellized model field. Also apparent is the underestimation of albedo in the most cloudy regions: overcast model pixels commonly indicate $\alpha \approx 0.3$, while the main convective centres in the GERB data contain $\alpha>0.5$. While there is extensive model layer-cloud fraction at 10-15 km altitude (Figure 4(c)), the model underestimation of albedo is related to the convective-cloud fractions that are below $10 \%$ for much of the transect (contours in 4(c)).

Figure 5 shows the model and GERB ALBCF (calculated as the difference between albedo and model type II clear-sky albedo) and cloud fraction for the period April-September 2006. The model substantially underestimates the mean albedo over equatorial Africa, with $\alpha \approx 0.1$ compared with GERB values between about 0.15 and 0.2. The model appears to underestimate cloud fraction over western equatorial Africa; this helps to explain some of the discrepancy in albedo. However, cloud fraction is generally overestimated by the model over eastern equatorial Africa (Figure 1(c)), and when ALBCF is normalized by cloud fraction (essentially removing the effect of cloud fraction on the ALBCF differences) a negative model bias prevails. This suggests an unrealistically low cloud reflectivity, indicating that cloud is not deep enough, a likely symptom of underestimated convectivecloud fraction.

The model RSR underestimation over equatorial Africa over the period April-November resulted from an update in the model parametrizations on 14 March 2006 relating to convective clouds (Table I). Nevertheless, even before this model update, the spatial structure and reflectivity of convective cloud was prone to large errors (Milton et al., 2005; Allan et al., 2006): for example, probability histograms for the period 8-12 March indicate an overestimated probability for $\alpha<0.2$ and an underestimated probability for $\alpha>0.6$ (not shown). Part of the problem arises from the unrealistic intermittency of convection and convective-available-potential-energy closure adjustment time-scales (Milton et al., 2005). The 14 March model updates exacerbated the problem with a substantial model underestimation in the probability of $\alpha>0.3$ over the period April-November 2006.

To alleviate the problem of intermittency of convection, a decay time-scale was introduced into the model convection parametrization on 5 December 2006. Figure 6 illustrates the improvement in model simulation of albedo over the equatorial African region compared with GERB data, relative to the earlier comparison in Figure 4. The vertical cross-sections of model cloud in Figure 6(c) show an increased convective-cloud coverage, explaining the increased albedo, although large-scale cloud appears less extensive than in Figure 4(c). CloudSat cloud-mask data are also shown for a similar crosssection in Figure 6(d), and highlight the extensive convective cloud, in particular south of the Equator. These comparisons suggest that the model still fails to simulate the highest albedo values, and a slight underestimate in cloud fraction and albedo remains (Figure 3(d)).

\subsection{Diurnal cycle over tropical Africa}

The diurnal cycle of tropical convection has long been a problem for general circulation models (e.g. Slingo et al., 2004). We now consider changes over equatorial Africa 


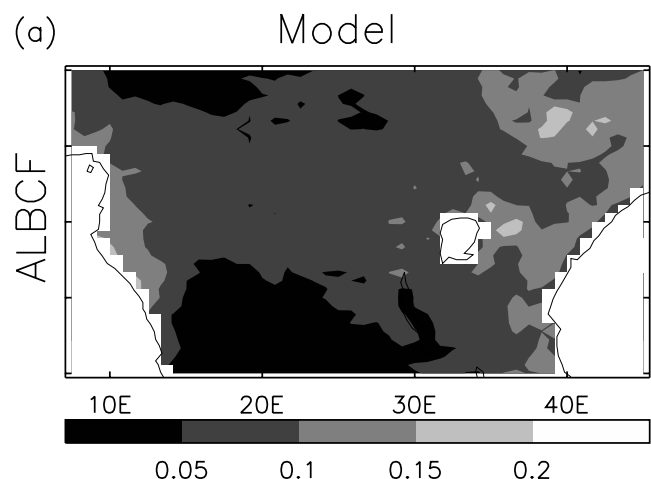

(b)

\section{GERB}

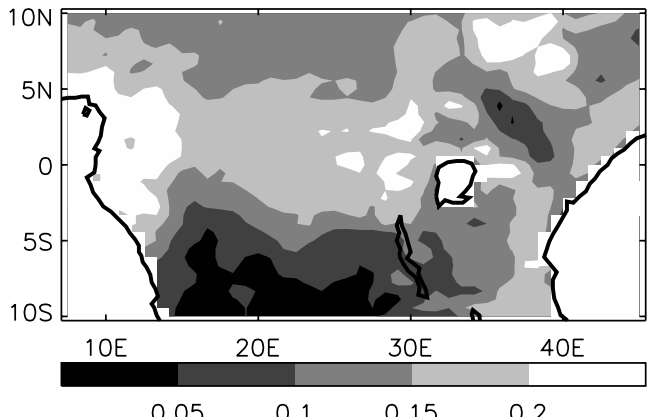

(c)

(d)
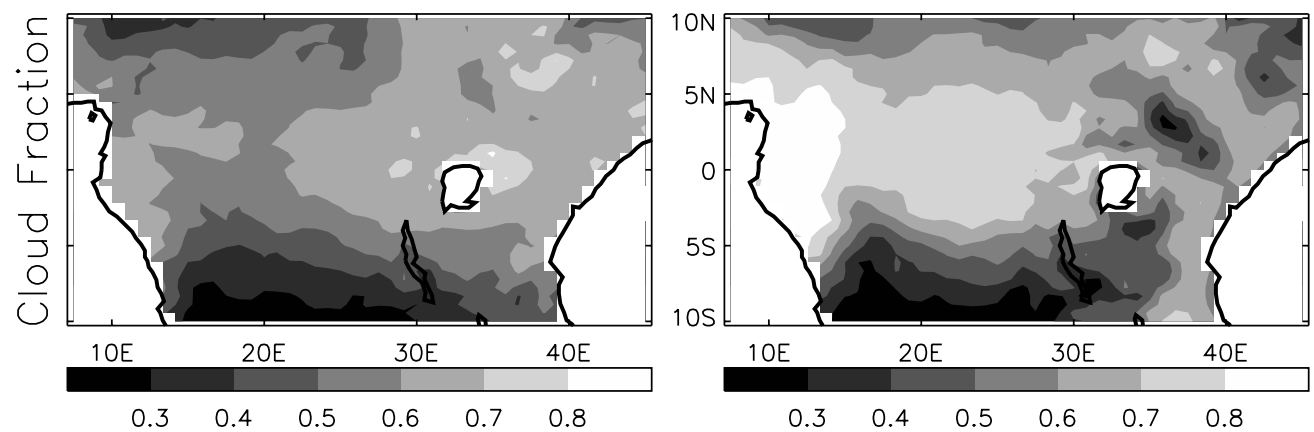

(e)

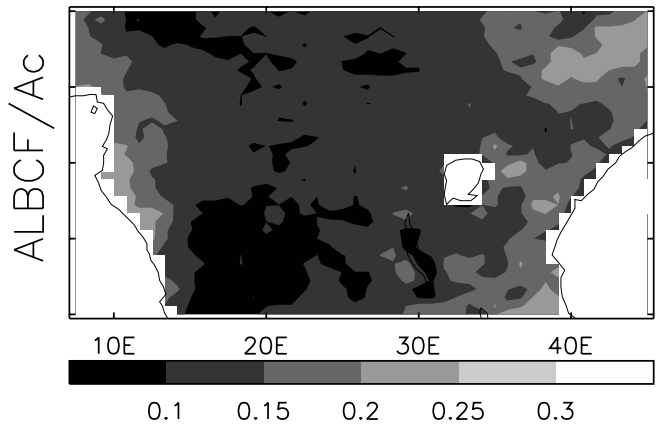

(f)

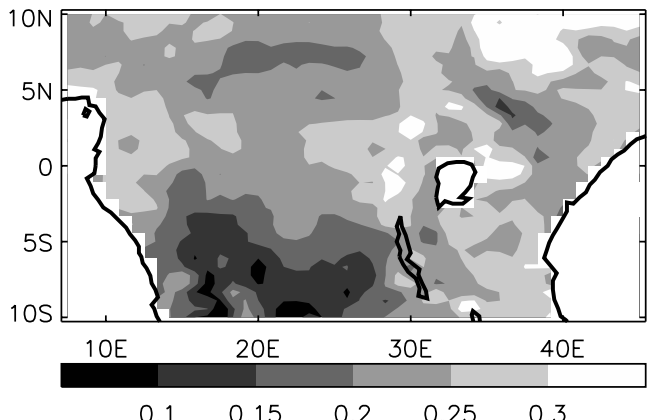

Figure 5. Mean short-wave albedo cloud radiative forcing at 12 UTC (April-September 2006) over equatorial Africa: ALBCF for (a) model and (b) GERB; $A_{\mathrm{c}}$ for (c) model and (d) Meteosat-8; cloud albedo forcing normalized by cloud fraction $\left(A L B C F / A_{\mathrm{c}}\right)$ for (e) model and (f) GERB.
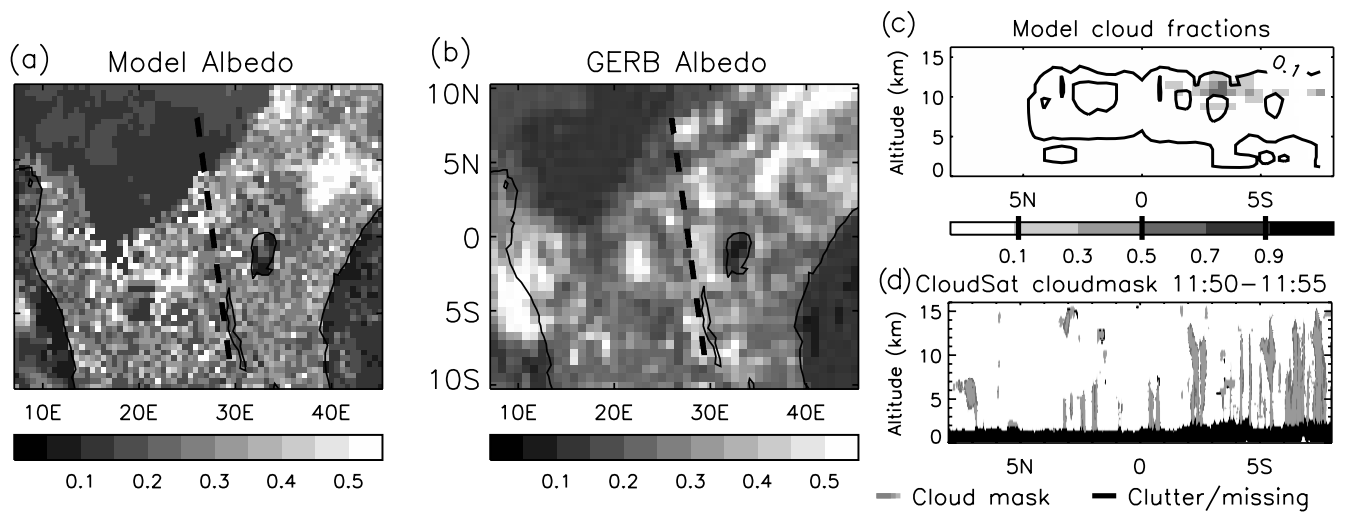

Figure 6. Short-wave albedo at 12 UTC on 5 December 2006 over equatorial Africa, for (a) the model (including convective-cloud-decay time-scale parametrization and using original model spatial resolution) and (b) GERB data. Vertical cross-sections (corresponding to the dashed lines in (a) and (b)) of (c) model large-scale cloud (shading) and convective cloud (contours) and (d) CloudSat cloud mask. 


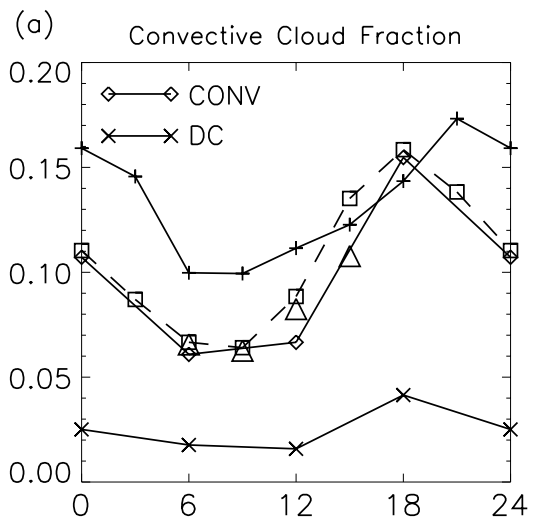

(c)

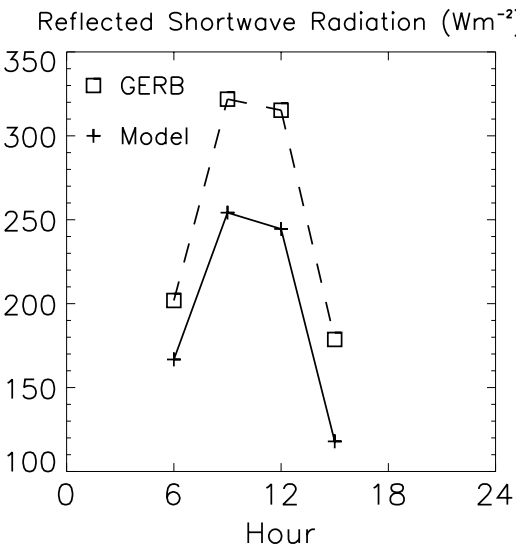

(b)

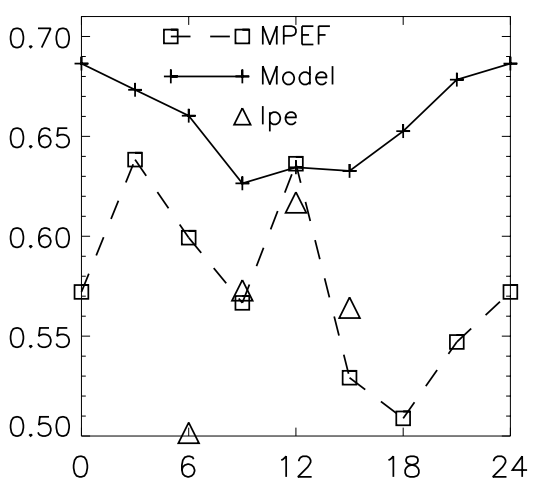

(d)

Outgoing Longwave Radiation $\left(\mathrm{Wm}^{-2}\right)$

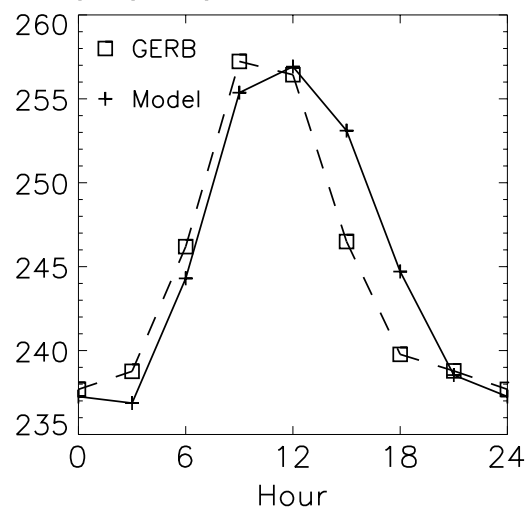

Figure 7. July 2006 average diurnal cycle, over equatorial Africa $\left(7^{\circ}-45^{\circ} \mathrm{E}, 10^{\circ} \mathrm{S}-10^{\circ} \mathrm{N}\right)$, in: (a) convective cloud; (b) total cloud; (c) RSR; (d) OLR. Also shown in (a) are narrow-band BTs used as measures of convective cloud: 'DC' is the proportion of pixels where $6.3 \mu \mathrm{m}$ BT minus $10.8 \mu \mathrm{m} \mathrm{BT}$ is positive, and 'CONV' is the proportion of pixels where $6.3 \mu \mathrm{m}$ BT is less than $225 \mathrm{~K}$.

$\left(7^{\circ}-45^{\circ} \mathrm{E}, 10^{\circ} \mathrm{S}-10^{\circ} \mathrm{N}\right)$ for the July mean diurnal cycle at a frequency of $3 \mathrm{~h}$ (Figure 7 ). In addition to comparing changes in area-average cloud fractions and the radiation budget, we also diagnose the fraction of convective-cloud cover, using the following criterion:

$$
\left.\begin{array}{cc}
\frac{L W C F}{A_{\mathrm{c}}} & >80 \mathrm{Wm}^{-2} \\
A_{\mathrm{c}} & >0.9
\end{array}\right\} .
$$

This ensures that high-altitude extensive cloud is sampled consistently in the model and GERB data; thick cirrus anvils may also be included in this identification as well as deep convective cloud.

The three-hourly convective-cloud averages, as identified in the model, MPEF and IPE cloud diagnostics, are presented in Figure 7(a). Also shown are measures of deep convective (DC) and convective (CONV) clouds based on SEVIRI channels. The value of DC is defined as the proportion of pixels for which $6.3 \mu \mathrm{m}$ brightness temperature (BT) minus $10.8 \mu \mathrm{m} \mathrm{BT}$ is positive (e.g. Soden, 2000); and CONV is defined as the proportion for which $6.3 \mu \mathrm{m} \mathrm{BT}$ is less than $225 \mathrm{~K}$ (e.g. Nowicki and Merchant, 2004). The MPEF and IPE cloud diagnostics identify much more convective cloud than the DC parameter, but are comparable to the CONV measure, confirming that the criterion used to identify convective cloud in Equation (5) samples both deep convective and cirrus anvil cloud associated with convection and is directly comparable to previous estimates using narrowband water-vapour-channel radiances (e.g. Nowicki and Merchant, 2004). The IPE cloud product is only available for the 06-15 UTC time slots; there is good agreement with MPEF, although IPE is lower for 15 UTC, partly because of missing data in the east where the solar zenith angle is low.

Comparing the diurnal changes in convective cloud (Figure 7(a)), we see that the model slightly overestimates convective-cloud fraction, except at 15 and 18 UTC. The MPEF-diagnosed convective-cloud fraction peaks at $18 \mathrm{UTC}, 3 \mathrm{~h}$ before the model peak. This is at odds with the finding of Slingo et al. (2004) that the model convective cloud and precipitation peak earlier in the day than observations from Meteosat, although the model and methodology of that study differ substantially from the present analysis.

A general overestimation in model total-cloud fraction is also apparent (Figure 7(b)). This bias is of the wrong sign to explain the lower RSR in the model compared with GERB (Figure 7(c)). The anomalously low IPE total-cloud fraction at 06 UTC is influenced by missing data and higher uncertainty at the low sun angles. Interestingly, the MPEF total-cloud-fraction minimum coincides with the peak in diagnosed convective cloud, while the model total- and convective-cloud fractions are 
in phase to within about $3 \mathrm{~h}$. The diurnal cycle of MPEF cloud fraction is complex, and merits further discussion. In particular, the peak in cloud fraction at 12 UTC, also seen in the IPE data, is at odds with the model estimates and the diagnosed convective cloud in Figure 7(a). Since this peak is not present in the convective-cloud changes, it is plausible that the signal originates from low-altitude cloud. Indeed, previous analysis of diurnal changes in cloud cover over the adjacent Gulf of Guinea $\left(10^{\circ} \mathrm{W}-10^{\circ} \mathrm{E}, 5^{\circ}-10^{\circ} \mathrm{N}\right)$ by Futyan et al. (2005) also indicates a peak in low cloud around this time. However, it is possible that temperature-dependent errors are spuriously identifying more low-altitude cloud at this time; this requires further analysis.

Despite the large cloud fractions in this convectivelyactive region, the diurnal changes in area-mean OLR are strongly affected by solar heating of the land (Comer et al., 2007), as highlighted by the peak close to 12 UTC in both the model and the GERB data (Figure 7(d)). The model captures the diurnal cycle in GERB OLR, despite the apparent overestimation of total- and convectivecloud fractions compared with IPE and MPEF. At 15 and 18 UTC, where model and observed convective-cloud fraction agree to within 0.01 , the model overestimates OLR, compared with GERB. Considering the probability histogram of OLR at 15 UTC (not shown), it seems likely that the higher model OLR originates from clear regions (highest OLR values) far from the convective centres.

\section{Convectively-generated cloud over the Gulf of Guinea}

A negative model OLR bias over the Gulf of Guinea (Figure 1(a)) coincides with a region of active convection and cirrus cloud (Comer et al., 2007). Analysing the model data in more detail, it is also apparent that higheraltitude cloud, inferred from its strong effect on OLR and relatively weak effect on short-wave albedo at midday, is often present. Detailed comparisons of model and GERB OLR over the extended Gulf of Guinea region $\left(29^{\circ} \mathrm{W}-12^{\circ} \mathrm{E}, 15^{\circ} \mathrm{S}-15^{\circ} \mathrm{N}\right)$ are now conducted using three-hourly data for July 2006.

Figure 8 shows the time-latitude evolution of OLR (shading) for the model and GERB. Overlayed are contours of MPEF cloud fraction at $40 \%$ and $80 \%$, smoothed over $12 \mathrm{~h}$ for clarity. In general, the model overestimates cloud fraction compared with MPEF; this is consistent with the negative OLR bias in Figure 1(a). Active convection, with low OLR and high cloud cover, dominates at $5{ }^{\circ} \mathrm{N}$. The strongest events appear around 4-7 July, 14-16 July and 29-31 July in both the model and the GERB data, although OLR is lower in the model simulations.

The 4-7 July event is also accompanied by an extension of the region of low OLR to the south in both the model and the GERB data. The magnitudes of OLR and cloud-fraction anomalies are slightly underestimated by the model. Similar southward movement of cloud bands in the model around 15 July and over the period 18-24 July are not present in the satellite data; hence there are underestimates in model OLR of almost $100 \mathrm{Wm}^{-2}$ at $5^{\circ} \mathrm{S}$ on $20 \mathrm{July}$. To investigate the cause of this discrepancy, we consider 12 UTC data on 5 and 19 July (marked as thick vertical lines in Figure 8).

Figure 9(a,b) shows maps of model and GERB OLR fields over the Gulf of Guinea (shading) for 12 UTC on 5 July. Superimposed are contours of $500 \mathrm{hPa}$ vertical velocity (solid contours represent upward motion, dashed contours descent) from the model and the NCEP reanalysis. Although there are deficiencies in the NCEP

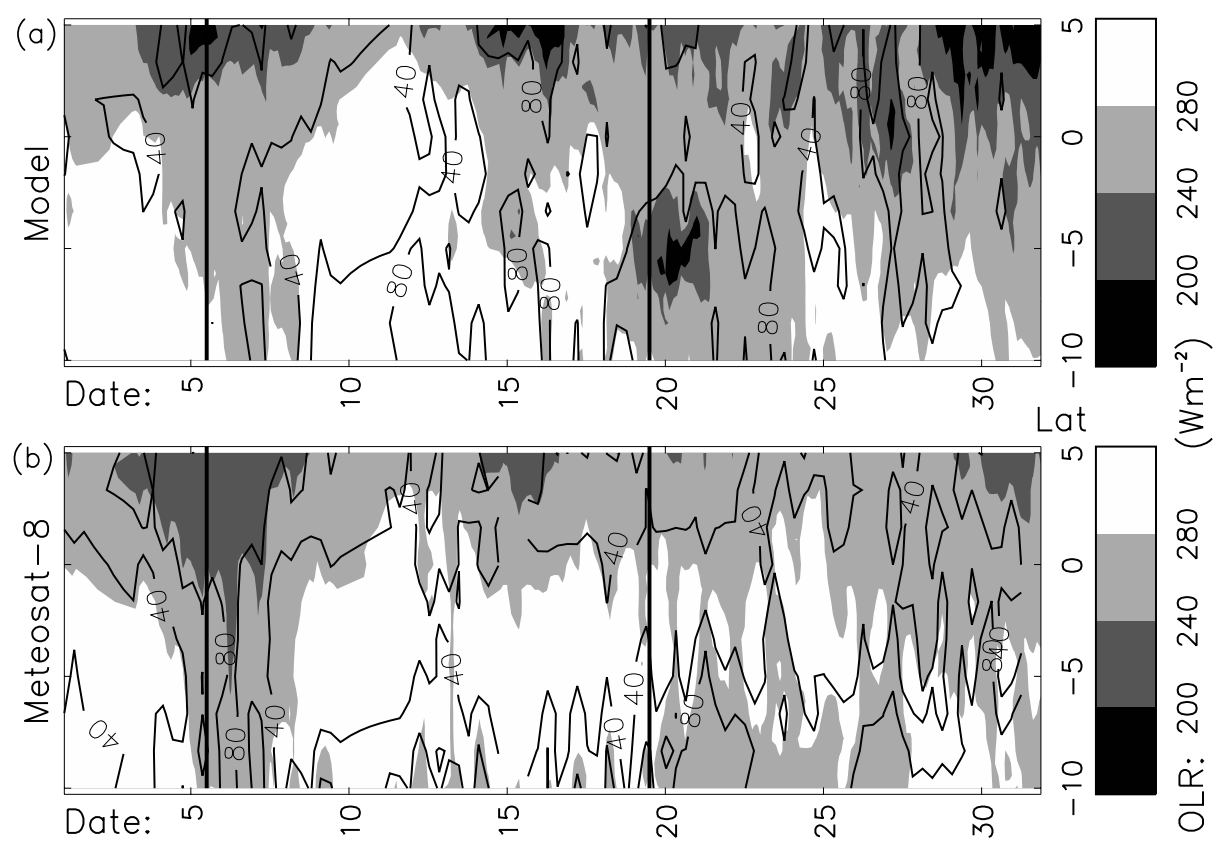

Figure 8. Time-latitude evolution of OLR (shading) and cloud fraction (contours), for (a) model and (b) GERB/MPEF, during July 2006, using coincident three-hourly data over the region $\left(10^{\circ} \mathrm{W}-5^{\circ} \mathrm{E}, 10^{\circ} \mathrm{S}-5^{\circ} \mathrm{N}\right)$. Horizontal lines are centred at $12 \mathrm{UTC}$ on 5 and $19 \mathrm{July}$. 

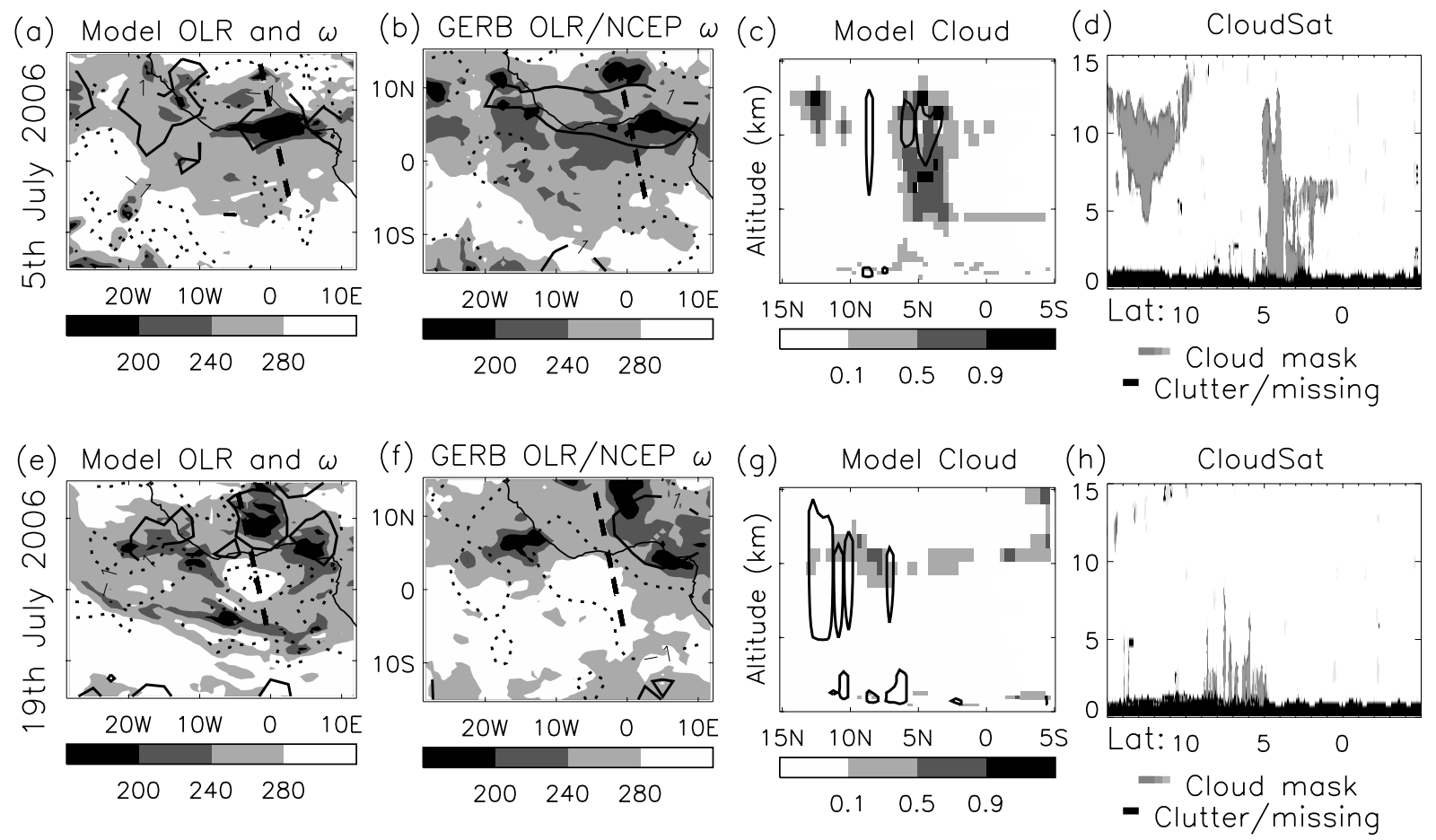

Figure 9. Case studies for (a,b,c,d) 5 July and (e,f,g,h) 19 July 2006. Maps of OLR (shading) and contours of vertical velocities at $1 \mathrm{~cm} \mathrm{~s}^{-1}$ (solid) and $-1 \mathrm{~cm} \mathrm{~s}^{-1}$ (dotted), for (a,e) model and (b,f) GERB/NCEP data. Dashed lines indicate the vertical cross-sections for (c,g) the model, with shading representing layer cloud and contours of convective-cloud amounts (contours at 0.1, 0.5 and 0.9), and (d,h) a coincident CloudSat cloud mask.

data (e.g. Trenberth and Guillemot, 1998), it is useful to consider an independent analysis system in assessing the atmospheric circulation patterns.

The main area of convection over the Gulf of Guinea at $5^{\circ} \mathrm{N}$ is well captured by the model, although a secondary, mature convective system at $12^{\circ} \mathrm{N}$ is not present in the model. This is highlighted by the vertical crosssections of model layer-cloud (shading) and convectivecloud (contours) fractions in Figure 9(c) and the CloudSat cloud mask in Figure 9(d). Upward vertical motion is present in both the NWP model and the NCEP reanalysis for the $5^{\circ}-10^{\circ} \mathrm{N}$ region. The region of depressed OLR (less than $280 \mathrm{Wm}^{-2}$ ) running south from the main convective bands is well represented by the model, consistent with Figure 8. Analysing the EUMETSAT dust product (http://oiswww.eumetsat.org/SDDI/html/product_des cription.html), which uses the $12.0 \mu \mathrm{m}, 10.8 \mu \mathrm{m}$ and $8.7 \mu \mathrm{m}$ SEVIRI channels (not shown), we find that the extensive area of low OLR corresponds to thick midlevel cloud rather than cirrus. This is also apparent in the CloudSat data (Figure 9(d)), which show detrainment to the south around the freezing level at $6 \mathrm{~km}$, and is also present in the model at around $5 \mathrm{~km}$ (Figure 9(c)).

On 19 July, the model simulations contain bands of thick, higher-altitude clouds protruding across the equatorial Atlantic. These are not present in the GERB data, so there are local model underestimates in OLR approaching $100 \mathrm{Wm}^{-2}$. The model does capture the convective centres over and to the northwest of the Gulf of Guinea and off the coast of Sierra Leone. It is not immediately clear why the model accurately simulates the extensive high-altitude cloud on 5 July but not on 19 July. Comparing the vertical-velocity fields, there is some evidence to suggest that the convective region is less extensive on 19 July than on 5 July for the NCEP data while the model vertical-motion fields are consistent between the two dates. Also, the NCEP data indicate a much larger region of strong subsidence to the southwest of the Gulf of Guinea on 19 July, which may act to reduce humidity, thereby dissipating cirrus cloud.

Another possibility is that cirrus cloud is present in the GERB data but is optically very thin. To test this hypothesis, BTs from SEVIRI channels are displayed in Figure 10. The $6.3 \mu \mathrm{m} \mathrm{BT}$, sensitive to high-altitude cloud and mid- to upper-tropospheric relative humidity (e.g. Brogniez et al., 2006), highlights the three main convective centres (with BT around $225 \mathrm{~K}$ ) present in the GERB OLR field. Much of the ocean region to the south of the African coast experienced high BT (around $245 \mathrm{~K}$ ), symptomatic of a dry, cloud-free upper troposphere. The $10.8 \mu \mathrm{m}$-minus-12 $\mu \mathrm{m}$ BT difference is sensitive to mineral-dust aerosol (negative BT difference) and to thin cirrus cloud (BT difference greater than $5 \mathrm{~K}$ ) (e.g. Luo et al., 2002; Chaboureau et al., 2007). This shows positive differences of around $5 \mathrm{~K}$ over continental Africa, probably coinciding with cirrus cloud, but BT differences over the ocean are generally around $2 \mathrm{~K}$, suggesting that thin cirrus is not present. Overlayed in Figure 10 (b) is the $80 \%$ contour of MPEF cloud; this highlights the main convective centres, as well as an area of marine stratocumulus cloud to the southeast of the region. 
(a)

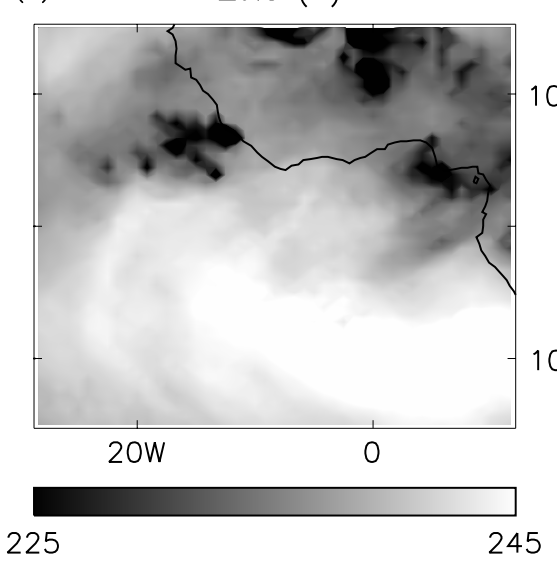

(b) $\quad \Delta \mathrm{T}-10.8-12(\mathrm{~K})$

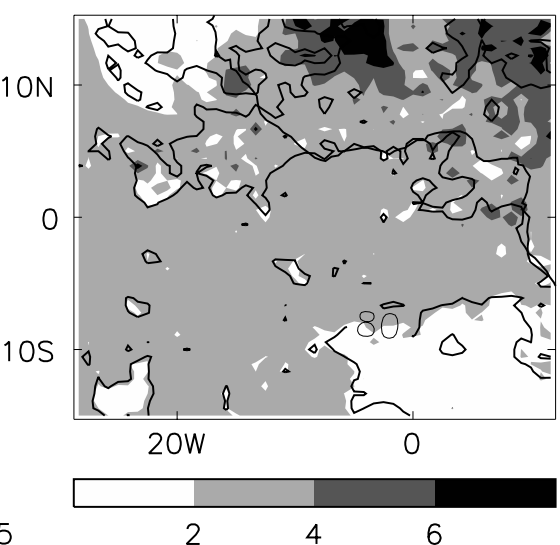

Figure 10. SEVIRI BTs for 19 July: (a) $6.3 \mu \mathrm{m} \mathrm{BT}$; (b) $10.8 \mu \mathrm{m}$-minus-12 $\mu \mathrm{m}$ BT difference. The MPEF $80 \%$ cloud-fraction contour is overlayed in (b).

Considering vertical cross-sections of model and observed cloud structure (Figure $9(\mathrm{~g}, \mathrm{~h})$ ), a layer of cirrus at around $10 \mathrm{~km}$ is present in the model data, extending south from continental convective cloud at $10^{\circ}-15^{\circ} \mathrm{N}$. This cloud is not detected by CloudSat, although some immature low-level convection, with cloud tops around $5 \mathrm{~km}$, is present at $5^{\circ}-10^{\circ} \mathrm{N}$. In summary, the negative model bias in OLR over the Gulf of Guinea appears to be related to the erroneous advection of high-level cloud from the north. Further analysis is required to identify the cause of this; it is possible that errors in convective processes, including detrainment, are contributing.

\section{Subtropical low-level cloud in the South Atlantic}

The effect of low-level stratiform clouds on the top-ofatmosphere radiation budget is large, since they readily reflect sunlight while exerting only a marginal effect on the long-wave radiative cooling to space. The net radiative cooling effect of these clouds is particularly large at local noon, when the insolation is maximal, and over ocean surfaces, since the cloud reflectivity (or albedo) is much larger than that of the ocean surface. While it is therefore important to simulate marine stratiform or stratocumulus clouds in models, this is by no means trivial. Marine stratus tends to form beneath the subtropical dry descending branches of the Hadley circulation over cold ocean currents, generally to the west of continents (e.g. Klein and Hartmann, 1993): these conditions favour subsidence, which limits the growth of cumulus convection and maintains a moist boundary layer. Therefore the representation of stratocumulus cloud in models is highly sensitive to detailed structure in the boundary layer and the interaction between the boundarylayer and convection schemes.

Considering 12 UTC data over the period AprilSeptember 2006, we find that the largest positive modelminus-GERB RSR bias (about $60 \mathrm{Wm}^{-2}$ ) occurs over the subtropical Atlantic ocean (Figure 1(d)), coinciding with regions of extensive low-level cloud cover, including the primary marine stratocumulus belts, consistent with previous findings (Allan et al., 2006). Variability in the model oceanic albedo bias (Figure 2(d)) coincides with updates to the physical parametrizations, including the boundary-layer scheme. The primary aims are therefore to assess the variations in model bias over time, whether errors in cloud amount or reflectivity can explain the model bias, and the effect of model changes on the simulation of low-level marine stratiform cloud over the period. (a)

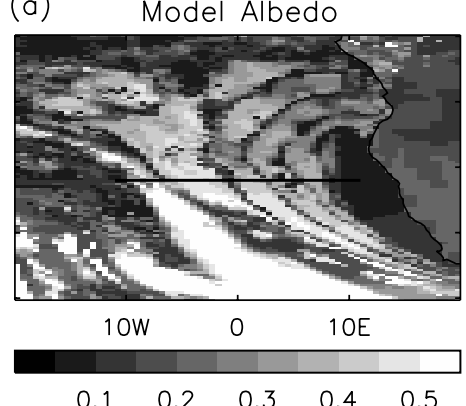

(b)

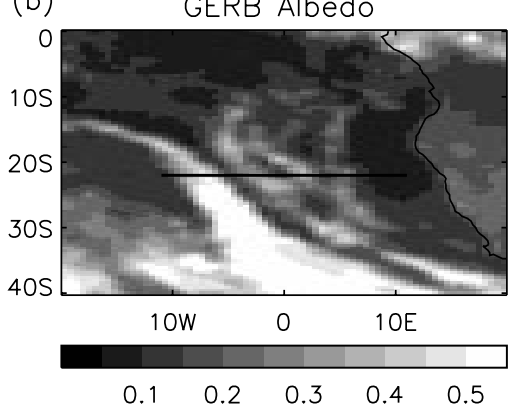

(c)

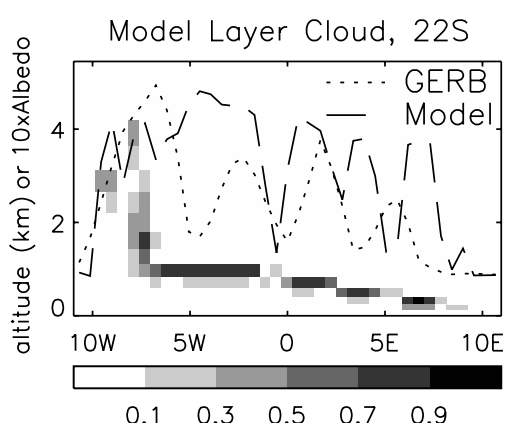

Figure 11. Short-wave albedo at 12 UTC on 5 June 2006 over the southeastern subtropical Atlantic, for (a) model (original resolution) and (b) GERB data. (c) Model large-scale cloud fraction (shading) and the GERB and model albedo (lines) for a vertical cross-section (horizontal lines in (a) and (b)). 


\subsection{Spatial structure and radiative properties}

Figure 11 shows the model and GERB short-wave albedo at 12 UTC over the South Atlantic stratocumulus region for 5 June 2006. Consistent with previous comparisons (Allan et al., 2005), the model cloud coverage exhibits a curious banded structure, thought to relate to an unrealistic representation of the rising cloud-top altitude with increasing boundary-layer depth to the west, possibly due to inadequate vertical resolution (Lock, 2001). This is further illustrated in Figure 11(c), which shows a cross-section (represented by horizontal lines in Figure 11(a,b)) of model layer-cloud fraction and the model and GERB albedo. Model layer-cloud-top altitude rises towards the west; as it does so, there is reduced cloud cover in the regions of cloud transitions between vertical model layers. These regions also coincide with sharp troughs in model albedo, although it is interesting that the GERB data also indicate peaks and troughs in albedo. At about $7^{\circ}-8^{\circ} \mathrm{W}$, an area of deeper cloud corresponds to a region of frontal cloud extending from the southeast, identified by the brightest region in both the model and the GERB albedo fields.

Consistent with previous analysis over the period 2003-2005 (Allan et al., 2006), the cloudy region appears brighter in the model than in the GERB data
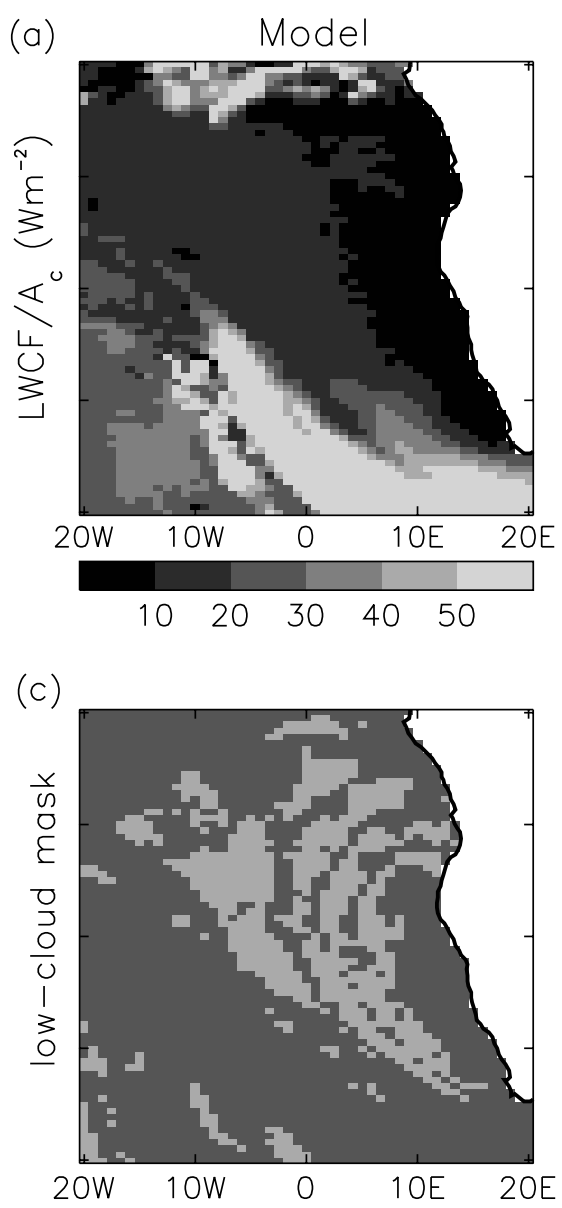

(Figure 11). We now assess the radiative properties of low-level cloud for this region.

To identify low-level stratiform cloud, we adopt a simple method that allows consistent sub-sampling of the GERB and model data. To achieve this, we use top-ofatmosphere radiative fluxes and cloud fractions available from the Meteosat- 8 satellite and simulated by the NWP model. Low-altitude overcast pixels are identified by:

$$
\left.\begin{array}{cc}
\frac{L W C F}{A_{\mathrm{c}}} & \leq 30 \mathrm{Wm}^{-2} \\
A_{\mathrm{c}} & >0.8
\end{array}\right\} .
$$

This criterion ensures the removal of higher-altitude cloud and low-level broken cloud cover, thereby concentrating on overcast low-altitude cloud scenes in the model and GERB data. It is qualitatively consistent with that of Futyan et al. (2005), who used SEVIRI cloud products to calculate the Meteosat-estimated contribution from high, medium and low cloud of short-wave and long-wave cloud radiative forcing. Although the identified scenes may contain various types of low-altitude cloud cover, for convenience we classify them as 'marine stratocumulus'. It is also possible that contamination by thin cirrus may occur; however, it is expected that the dominant type of cloud identified will be stratocumulus, as illustrated by Futyan et al. (2005) for June 2004 over the South Atlantic.

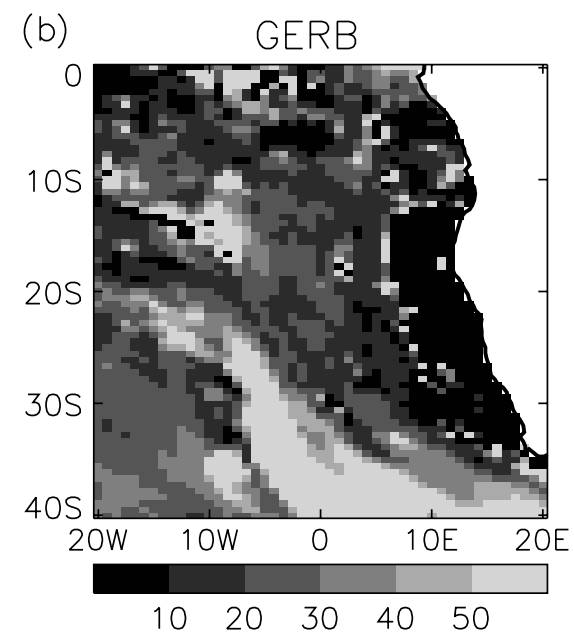

(d)

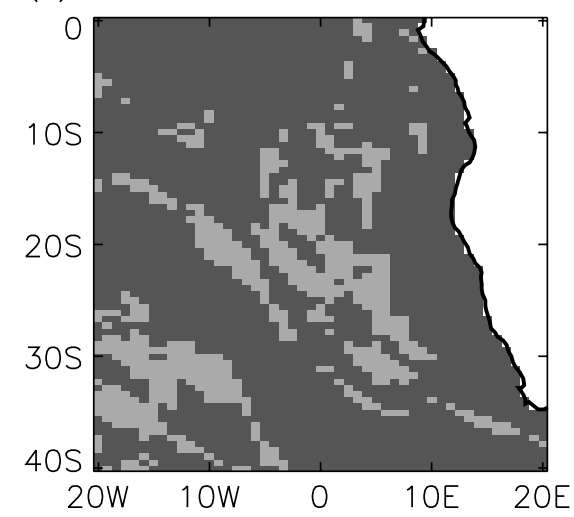

Figure 12. Illustration of low-level overcast pixel identification for 12 UTC on 5 June 2006: LWCF normalized by cloud fraction, $A_{\mathrm{c}}$, for (a) model and (b) GERB, and the low-cloud mask (light shading) for (c) model and (d) GERB. 
Figure 12(a,b) shows an example of the $L W C F / A_{c}$ parameter used in Equation (6). If $A_{\mathrm{c}}=0$, then $L W C F / A_{\mathrm{c}}$ is also set to zero. Values over $30 \mathrm{Wm}^{-2}$ are identified as high cloud: for example, the bright stripe of cloud running from $\left(10^{\circ} \mathrm{W}, 20^{\circ} \mathrm{S}\right)$ to $\left(0^{\circ}-10^{\circ} \mathrm{E}, 40^{\circ} \mathrm{S}\right)$. The cloud mask, determined from Equation (6), is shown in Figure 12(c,d). For this example, the model stratocumulus cloud is generally more extensive than in the satellite data, although more cloud is identified in the southwest of the region for the satellite data.

To analyse the spatial nature of biases in low-levelcloud properties, composites are formed based only on ocean grid points in which the model and observations both indicate stratocumulus-like cloud cover, according to Equation (6). A mean for the period April-September 2006 is calculated, removing grid points where coincident stratocumulus cover is not indicated more than $5 \%$ of the time. This also avoids extensive missing GERB data over the region during the period October-March. Figure 13 shows the resulting composites for LWCF, ALBCF, and the frequency of occurrence of stratocumulus cloud cover, in the model and GERB.

Figure 13 shows a slightly lower magnitude of LWCF in the model compared with GERB, although this is within the expected model clear-sky OLR uncertainty (Allan et al., 2005) used to construct both the model and the GERB LWCF estimates. The increase in LWCF from east to west, in both the model and GERB, is consistent with an increase in cloud-top altitude with increasing boundary-layer height (Figure 11(c)). However, while this progression is aligned east-to-west in the GERB data, it appears more northeast-to-southwest in the model.
A spatially similar increase in cloud albedo effect is present in the model, suggesting a thickening of the cloud with increasing boundary-layer depth. This effect is not apparent in the GERB data, which show ALBCF around 0.25 . Consistent with the mean comparisons, the model ALBCF is substantially larger than that found in the GERB data, ranging from 0.25 on the coast of Angola $\left(10^{\circ} \mathrm{E}, 10^{\circ} \mathrm{S}\right)$ to 0.35 to the southwest of the region considered. The frequency of occurrence of marine stratocumulus cloud in the model (Figure 13(c)) is similar to but slightly lower than that of the Meteosat data (Figure 13(f)). This suggests that the positive model bias in RSR shown in Figure 1 is caused by an overestimation of cloud reflectivity rather than cloud fraction, although Figure 1(c) suggests a slight model overestimation of cloud fraction to the north of the region.

\subsection{Daily to monthly variability}

Variations in cloud cover are presented in Figure 14, using the 12 UTC data from April-September 2006. To improve interpretation, a three-day moving average is applied to the data. Coinciding with a reduction in seasurface temperature, from $297 \mathrm{~K}$ in April to $293 \mathrm{~K}$ in August-September, is a general increase in cloud fraction (Figure 14(a)), although the model increases are weaker. Klein and Hartmann (1993) found a similar increase in cloud fraction over this region and related it to increased static stability that inversely followed changes in sea temperature.

Applying Equation (6), the resulting diagnosed variability of marine stratocumulus (Figure 14(b)) suggests that much of the variability in cloud fraction results from changes in low-level stratiform cloud cover. The model
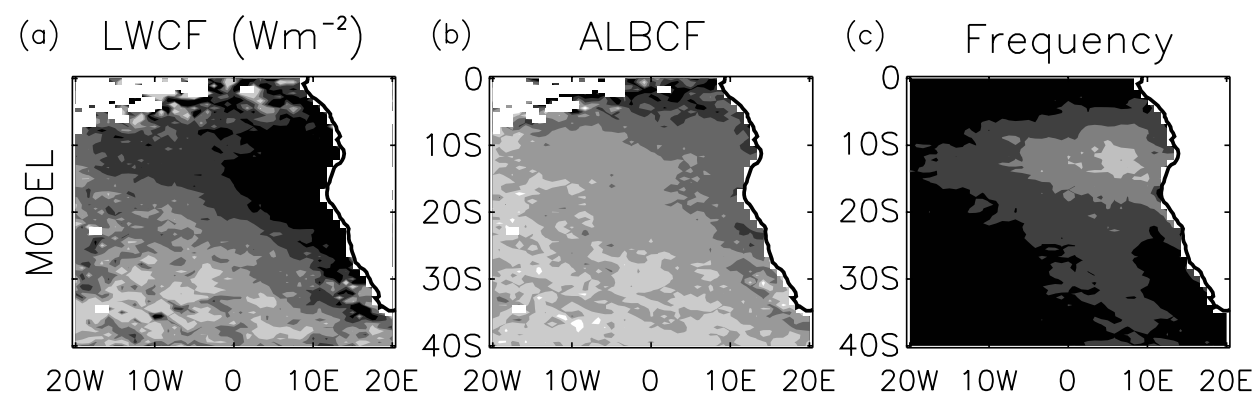

(d)

(e)
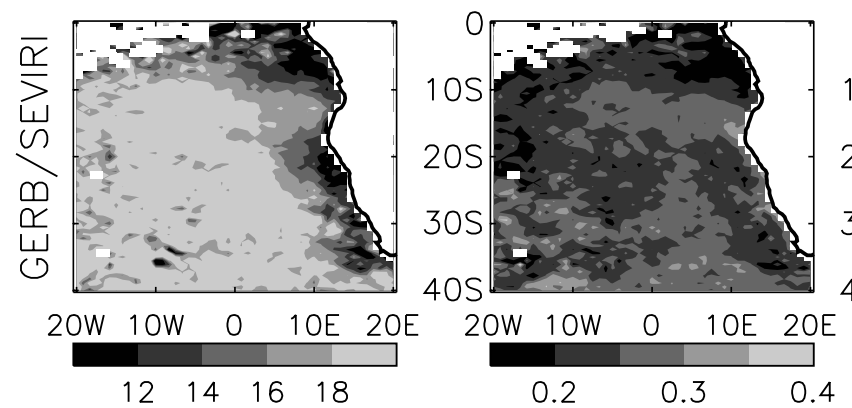

(f)

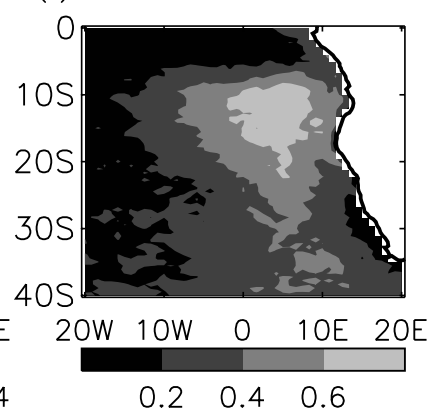

Figure 13. Composites of cloud radiative properties for pixels identified as low-level overcast cloud for 12 UTC data over the period April-September 2006: LWCF for (a) the model and (d) GERB/SEVIRI; short-wave ALBCF for (b) the model and (e) GERB/SEVIRI; frequency of occurrence of low-level overcast cloud in (c) the model and (f) GERB/SEVIRI. 


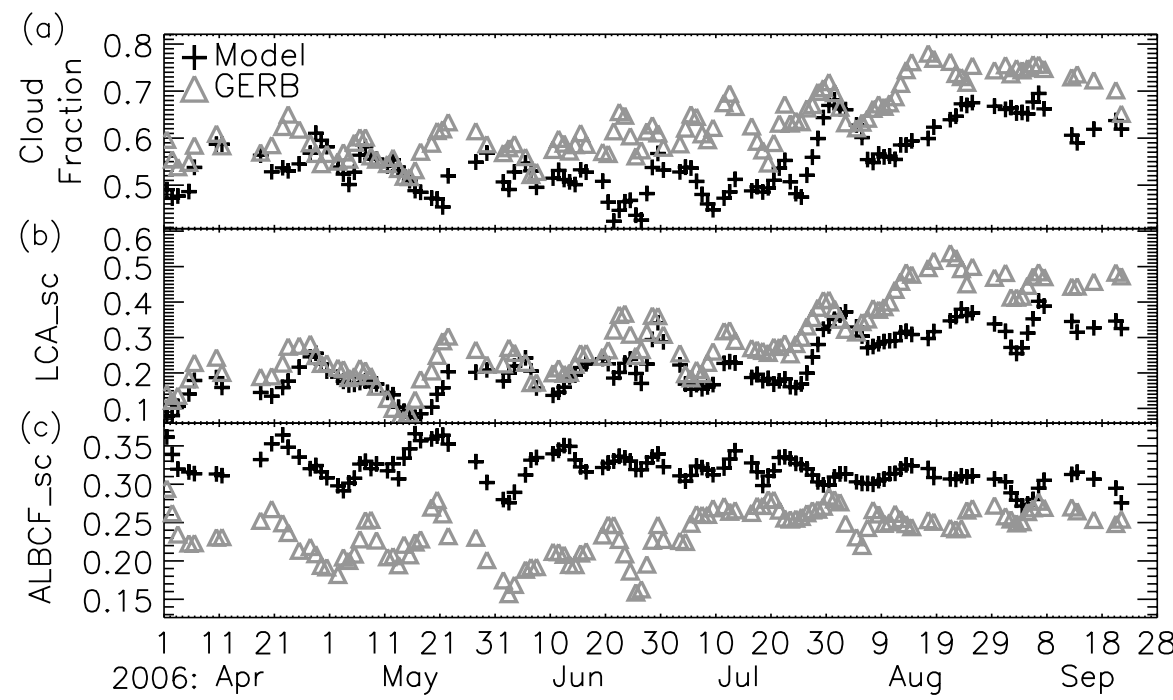

Figure 14. Ocean-only time series, at $12 \mathrm{UTC}$, for the model and GERB/SEVIRI, for April-September $2006\left(20^{\circ} \mathrm{W}-20^{\circ} \mathrm{E}, 0^{\circ}-40^{\circ} \mathrm{S}\right)$, of: (a) cloud fraction; (b) stratocumulus-like low-cloud amount; (c) stratocumulus-like cloud albedo effect. A three-day running mean has been applied.

(a)

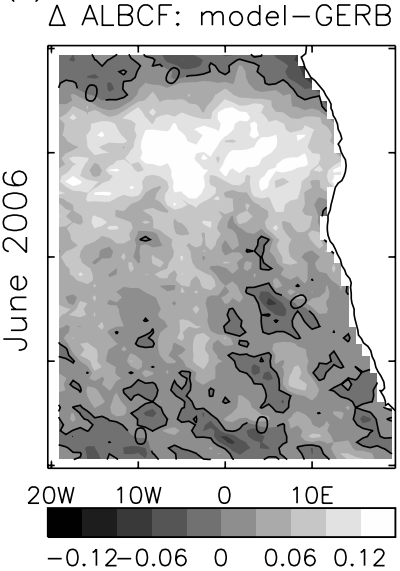

(d)

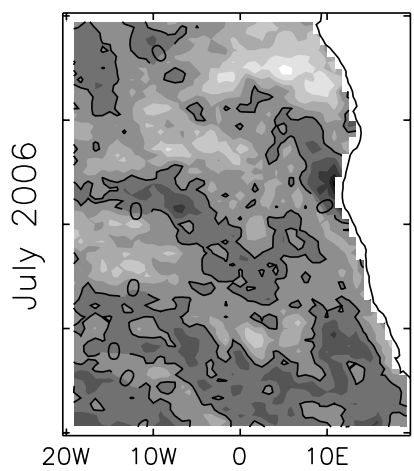

(b)

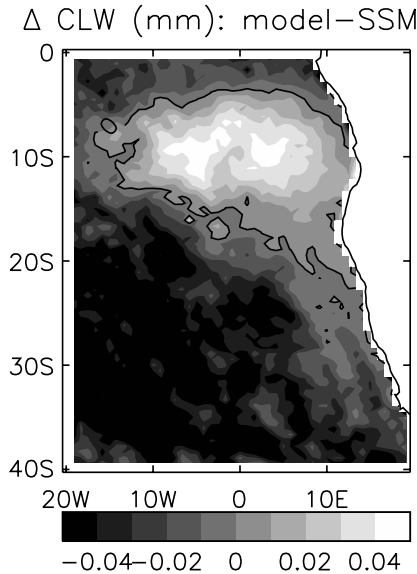

(e)

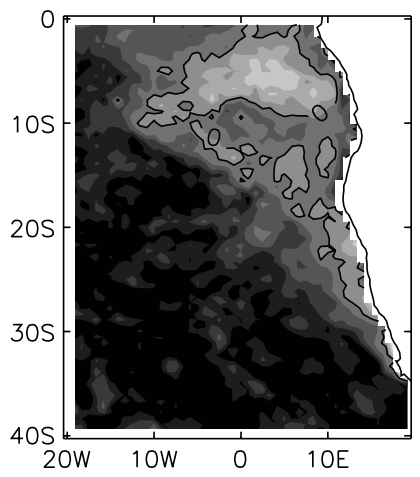

(c)

$\triangle A c:$ model-GERB

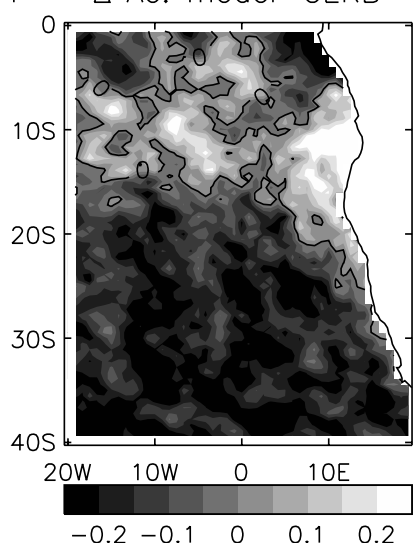

(f)

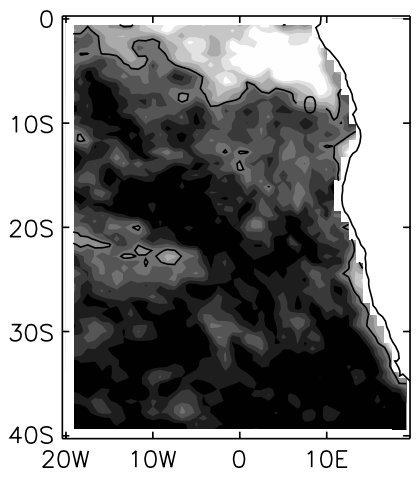

Figure 15. Differences between model and satellite estimates of cloud properties for $(a, b, c)$ June and (d,e,f) July 2006: (a,d) model-minus-GERB 12 UTC short-wave ALBCF; (b,e) model-minus-SSM/I daily-mean CLW; (c,f) 12 UTC model-minus-IPE cloud mask. A zero contour is included.

captures the weekly fluctuations and the monthly trend in stratocumulus cloud fraction, although it underestimates the cloud cover during August. The calculated ALBCF for the diagnosed stratocumulus cloud cover is presented in Figure 14(c). Only grid points where both the model and the observations indicate stratocumuluslike cloud cover are considered. This shows a systematic overestimation in stratocumulus cloud albedo, consistent with the mean comparisons in Figure 1. However, the differences become smaller from July 2006.

In Figure 15, we examine the apparent changes in model bias between June and July 2006. During June, a model overestimation in ALBCF at around $10^{\circ} \mathrm{S}$ corresponds to a model overestimation of CLW compared 
with data from SSM/I, but biases in cloud cover of variable sign (Figure 15(a,c)). By July, these biases in ALBCF and CLW have diminished, although a model overestimation in cloud cover to the north of the region coincides with a positive bias in ALBCF (Figure 15(d,e)). This suggests that the model biases in ALBCF in Figures 13 and 14 are related to overestimations in CLW over the period April-June 2006.

For both June and July, the model CLW is lower than the SSM/I values for the southwestern portion of the region (Figure 15). Over the global ice-free oceans, CLW is underestimated by a factor of two compared with SSM/I data; this is most pronounced across tropical oceans, close to the ITCZ and the South Pacific Convergence Zone (not shown). Recent comparisons of microwave and optical methods for deriving CLW (Horvatth and Davies, 2007) suggest that this discrepancy can be explained by shortcomings in the microwave retrievals for regions of clear skies and for moist tropical regions, relating to the use of older gaseous and liquid absorption models; comparisons for non-precipitating boundary-layer clouds agree to within $5 \%-10 \%$.

It is likely that the model CLW bias over stratocumulus regions can partly explain the bias in RSR, compared with GERB data, shown in Figure 1(d). It is also possible that assumptions employed in the model, such as plane-parallel radiative transfer, and in the retrievals - for example, assuming vertically homogeneous or adiabatically stratified CLW (e.g. Borg and Bennartz, 2007) - may contribute to the discrepancy. The reduction in model bias by July relates to an increase in GERB ALBCF and SSM/I CLW towards the model values; this suggests that the model has difficulty simulating seasonal fluctuations in marine stratocumulus properties.

\subsection{Diurnal cycle}

The diurnal changes in oceanic cloud and radiative fluxes over the southeastern Atlantic $\left(20^{\circ} \mathrm{W}-20^{\circ} \mathrm{E}, 0^{\circ}-40^{\circ} \mathrm{S}\right)$ are now diagnosed for July 2006 using three-hourly data. Figure 16(a) shows that the observed diurnal variation in diagnosed low-level stratocumulus is well captured by the model. There is a maximum coverage at 06 UTC, while minima occur at 15 UTC in the model and 18 UTC in the MPEF data. Also shown is the stratocumulus fraction calculated for the Ipe et al. (2004) short-wave cloud mask at 09,12 and 15 UTC used above; this shows a minimum at 12 UTC, illustrating that the observed diurnal cycle is sensitive to the cloud mask employed.

The total cloud fraction also displays a diurnal cycle (Figure 16(b)) that is of similar magnitude to, and therefore resulting from, the stratocumulus cloud variation. The total cloud fraction is more than twice the stratocumulus fraction, with low-level trade cumulus and higher-altitude cloud contributing to the total coverage. Both the MPEF and the IPE cloud fractions are greater
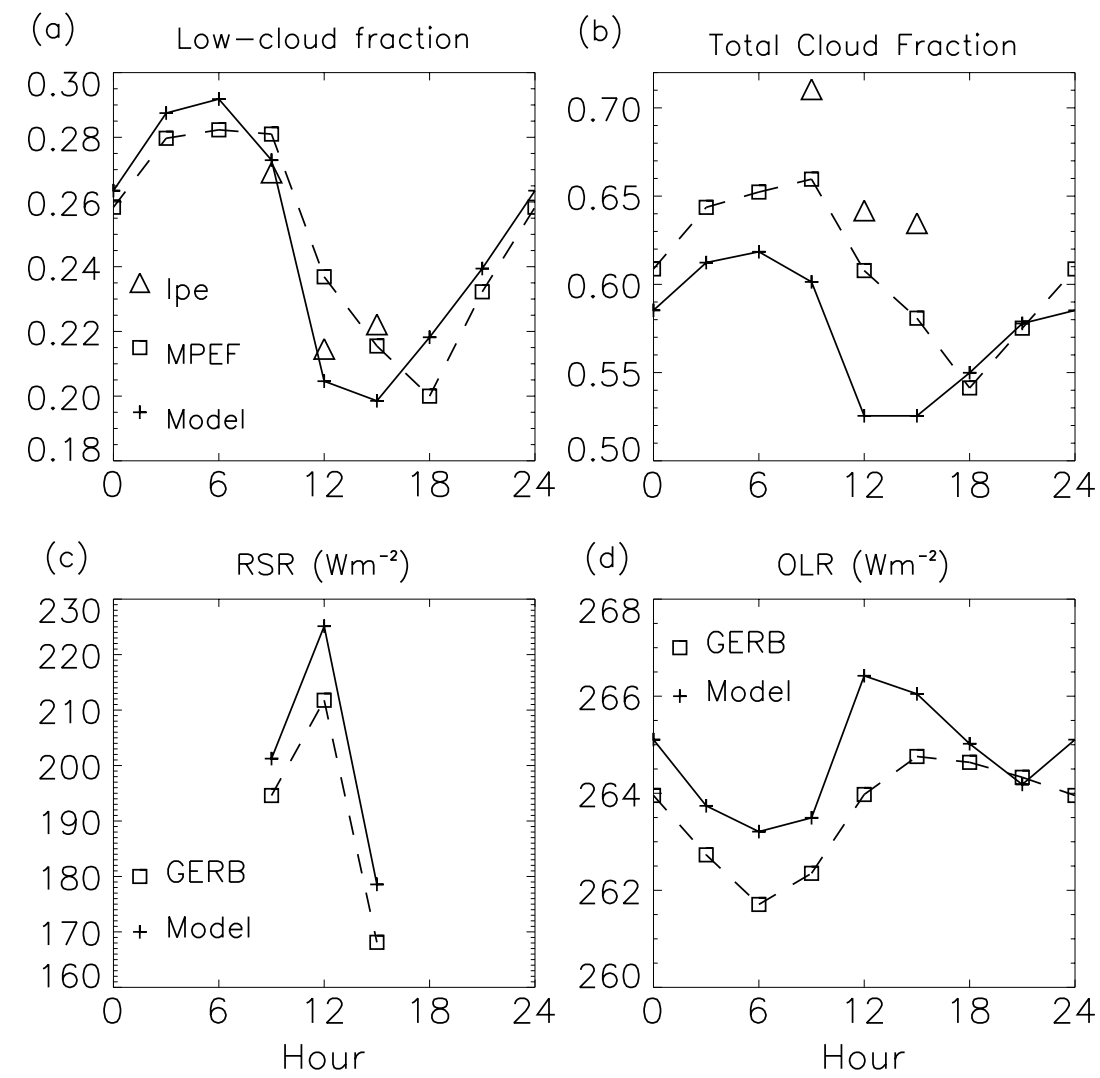

Figure 16. Mean diurnal cycle, using coincident three-hourly model and GERB/SEVIRI data over the ocean, for July $2006\left(20^{\circ} \mathrm{W}-20^{\circ} \mathrm{E}\right.$, $0^{\circ}-40^{\circ} \mathrm{S}$ ), of: (a) low-level stratocumulus-like cloud fraction; (b) total cloud fraction; (c) RSR; (d) OLR. 
than the model fraction by $5 \%-10 \%$ throughout the day apart from the evening; this mainly applies to the south of the region (Figure 15(f)), away from the primary stratocumulus decks.

Despite the model underestimate in cloud fraction, the simulated RSR is greater than the GERB values during the day by around $5-10 \mathrm{Wm}^{-2}$. This is consistent with the model stratocumulus cloud being too reflective, although the magnitude of the bias is small compared with the model-minus-GERB differences for the April-September period at 12 UTC displayed in Figure 1, because of the reduced CLW bias after June 2006 (Figure 15). Both model and GERB data indicate that the higher amounts of stratocumulus at 09 UTC compared with 15 UTC contribute to the higher RSR in the morning (around $200 \mathrm{Wm}^{-2}$ ) compared with the evening (around $180 \mathrm{Wm}^{-2}$ ).

The diurnal cycle of OLR (Figure 16(d)) corresponds well with the variation in cloud fraction, which in turn is primarily due to changes in stratocumulus. Thus, despite the low-altitude cloud-top heights, changes in stratocumulus exert a detectable influence on the OLR, although the magnitude of this variation is only around $3 \mathrm{Wm}^{-2}$. Similar results have been found by Comer et al. (2007) using principal-component analysis. The overestimate in model OLR (around $2 \mathrm{Wm}^{-2}$ ) is consistent with a lower non-stratocumulus fraction in the model, but these differences are within the expected uncertainty of the GERB data (Harries et al., 2005).

\section{Conclusions}

The Met Office global NWP model has been evaluated using new data from the GERB instrument on board the Meteosat- 8 satellite. Systematic differences between the model and GERB, exceeding the expected uncertainty in the satellite data, have been identified for 2006 .

- An overestimation in model OLR over the Sahara is primarily explained by the lack of representation of mineral-dust aerosol (Haywood et al., 2005).

- Despite an increase in model surface albedo over the Sahara to more realistic levels in January 2005 (Milton et al., 2005), there remain errors in the spatial structure of surface albedo based upon cloud-cleared comparisons during 2006. The model also underestimates clear-sky RSR by up to $100 \mathrm{Wm}^{-2}$ at $12 \mathrm{UTC}$ over the Sahel and northern coastal regions of Africa. Since 15 May 2007, an upgrade to the model (cycle G44) has included the implementation of a seasonallyvarying leaf-area index to replace the annual mean value and the use of MODIS data, to better prescribe the surface albedo of bare soil for sparsely-vegetated surfaces. This is currently improving the simulations of short-wave radiative fluxes in the model over Africa.

- A model underestimation in cloud fraction over Europe at 12 UTC explains model bias in top-of-atmosphere radiation during 2006.
- A model underestimation in short-wave albedo over equatorial Africa relates to unrealistic deep-convectivecloud properties. The bias is sensitive to the convective parametrization, and diminishes following the adoption of a convection decay time-scale within the model physics in December 2006, because of increased convective-cloud fraction.

- Unrealistic detrainment of convectively-generated southward-propagating cirrus-cloud bands over the Gulf of Guinea is identified during July 2006, leading to local underestimation in OLR by up to $100 \mathrm{Wm}^{-2}$.

- A model overestimation in short-wave albedo across the subtropical Atlantic ocean corresponds to areas of marine stratocumulus. The discrepancy is greatest for the period April-June, and is consistent with a model overestimation in CLW content compared with SSM/I data in June, which diminishes by July.

The combination of GERB data with additional information from other satellite instruments and reanalysis datasets provides a powerful tool for examining the causes of errors in the Met Office global NWP model. In addition to the monitoring of the satellite instruments, the comparisons enable timely evaluation of the NWP model, crucial for the development and implementation of new parametrizations. The methodology described will be continued, extending the current analysis period, and applied to both the NWP and the climate family of models, as more releaseversion GERB data become available. It is also planned to enhance these comparisons by making quantitative assessments of model simulations using satellite measurements of cloud structure, for example using the CloudSat simulator, and employing data from the CloudAerosol Lidar and Infrared Pathfinder Satellite Observations (CALIPSO).

\section{Acknowledgements}

Thanks to the GERB International Science Team for their input and the exhaustive work leading to the release of the Edition 1 GERB data. The GERB and SEVIRI data were taken from the GERB Ground Segment Processing System and RMIB archives. The CloudSat data were extracted from the CloudSat data-processing centre (www.cloudsat.cira.colostate.edu), the SSM/I data from www.ssmi.com, the MISR data from the NASA Langley Atmospheric Science Data Center, and the NCEP/NCAR reanalysis data from the NOAA Earth Systems Research Laboratory (www.cdc.noaa.gov). Two anonymous reviewers helped to improve the manuscript. This work was funded under NERC contracts NER/D/S/ 2002/00412 and NE/C51785X/1.

\section{References}

Allan RP, Slingo A, Milton SF, Culverwell I. 2005. Exploitation of geostationary Earth radiation budget data using simulations from a numerical weather prediction model: Methodology and data validation. J. Geophys. Res. 110: D14111. DOI:10.1029/2004JD005698. 
Allan RP, Slingo A, Milton SF, Brooks ME. 2006. 'Exploitation of geostationary Earth Radiation Budget (GERB) data from 2003-2006 in the evaluation of the Met Office global NWP model'. EUMETSAT P48, Proceedings of the EUMETSAT Meteorological Satellites Conference, 12-16 June 2006, Helsinki, Finland. EUMETSAT, Darmstadt, Germany. ISBN 92-9110-076-5.

Borg LA, Bennartz R. 2007. Vertical structure of stratiform marine boundary layer clouds and its impact on cloud albedo. Geophys. Res. Lett. 34: L05807. DOI:10.1029/2006GL028713.

Brogniez H, Roca R, Picon L. 2006. A clear-sky radiance archive from Meteosat 'water vapor' observations. J. Geophys. Res. 111: D21109. DOI:10.1029/2006JD007238.

Chaboureau J-P, Tulet P, Mari C. 2007. Diurnal cycle of dust and cirrus over West Africa as seen from Meteosat Second Generation satellite and a regional forecast model. Geophys. Res. Lett. 34: L02822. DOI:10.1029/2006GL027771.

Comer RE, Slingo A, Allan RP. 2007. Observations of the diurnal cycle of outgoing longwave radiation from the Geostationary Earth Radiation Budget instrument. Geophys. Res. Lett. 34: L02823. DOI:10.1029/2006GL028229.

Diner DJ, Abdou WJ, Conel JE, Crean KA, Gaitley BJ, Helmlinger M, Kahn RA, Martonchik JV, Pilorz SH. 2001. MISR aerosol retrievals over southern Africa during the SAFARI-2000 dry season campaign. Geophys. Res. Lett. 28: 3127-3130.

Edwards JM. 2007. Oceanic latent heat fluxes: consistency with the atmospheric hydrological and energy cycles and general circulation modeling. J. Geophys. Res. 112: D06115. DOI:10.1029/2006JD007324.

Futyan JM, Russell JE, Harries JM. 2005. Determining cloud forcing by cloud type from geostationary satellite data. Geophys. Res. Lett. 32: L08807. DOI:10.1029/2004GL022275.

Harries JE et al. 2005. The Geostationary Earth Radiation Budget project. Bull. Am. Meteorol. Soc. 86: 945-960.

Haywood JM, Allan RP, Culverwell I, Slingo A, Milton S, Edwards J, Clerbaux N. 2005. Can desert dust explain the outgoing longwave radiation anomaly over the Sahara during July 2003? J. Geophys. Res. 110: D05105. DOI:10.1029/2004JD005232.

Horváth Á, Davies R. 2007. Comparison of microwave and optical cloud water path estimates from TMI, MODIS and MISR. J. Geophys. Res. 112: D01202. DOI:10.1029/2006JD007101.

Ipe A, Clerbaux N, Bertrand C, Dewitte S, Gonzalez L. 2004. Validation and homogenisation of cloud optical depth and cloud fraction retrievals from GERB/SEVIRI scene identification using Meteosat-7 data. Atmos. Res. 72: 17-37. DOI:10.1016/j.atmosres.2004.03/010.

Kalnay EM, Kanamitsu M, Kistler R, Collins W, Deaven D, Gandin L, Iredell M, Saha S, White G, Woollen J, Zhu Y, Leetmaa A, Reynolds B, Chelliah M, Ebisuzaki W, Higgins W, Janowiak J, Mo KC, Ropelewski C, Wang J, Jenne R, Joseph D. 1996. The NCEP/NCAR 40-year reanalysis project. Bull. Am. Meteorol. Soc. 77: $437-471$.

Klein SA, Hartmann DL. 1993. The seasonal cycle of low stratiform clouds. J. Climate 6: 1587-1606.

Lock AP. 2001. The numerical representation of entrainment in parameterizations of boundary layer turbulent mixing. Mon. Weather Rev. 129: $1148-1163$
Loeb NG, Kato S, Loukachine K, Manalo-Smith N, Doelling DR. 2007. Angular distribution models for top-of-atmosphere radiative flux estimation from the Clouds and the Earth's Radiant Energy System instrument on the Terra Satellite. Part II: validation. J. Atmos. Oceanic Technol. 24: 564-584.

Luo Z, Rossow WB, Inoue T, Stubenrauch CJ. 2002. Did the eruption of the Mt. Pinatubo volcano affect cirrus properties. J. Climate 15 : 2806-2820.

Maidens AV, Derbyshire SH. 2007. Improving mass flux profiles in the Gregory-Rowntree convection scheme using adaptive detraimnent Q. J. R. Meteorol. Soc. (submitted).

Martin GM, Ringer MA, Pope VD, Jones A, Dearden C, Hinton TJ. 2006. The physical properties of the atmosphere in the new Hadley Centre Global Environment Model, HadGEM1. Part I: Model description and global climatology. J. Climate 19: 1274-1301.

Milton SF, Brooks M, Lock A, Whelan E, Wilson D, Allan R. 2005. 'HadGEM1 Physics for the Global NWP Model (Cycle G34): Improvements to Boundary Layer, Large Scale Precipitation, Convection and Saharan Albedo'. NWP Technical Report 458, Met Office, UK. 39 pp.

Milton SF, Greed G, Brooks ME, Haywood JM, Allan RP, Slingo A. 2007. Modelled and observed atmospheric radiation balance during the West African dry season - the role of mineral dust, biomass burning and surface albedo. (Submitted to J. Geophys. Res).

Nowicki SM, Merchant CJ. 2004. Observations of diurnal and spatial variability of radiative forcing by equatorial deep convective clouds. J. Geophys. Res. 109: D11202. DOI:10.1029/2003JD004176.

Rawlins F, Ballard SP, Bovis KJ, Clayton AM, Li D, Inverarity GW, Lorenc AC, Payne TJ. 2007. The Met Office Global 4-Dimensional Variational Data Assimilation Scheme. Q. J. R. Meteorol. Soc. 133: 347-362.

Schmetz J, Pili P, Tjemkes S, Just D, Kerkmann J, Rota S, Ratier A. 2002. An Introduction to Meteosat Second Generation (MSG). Bull. Am. Meteorol. Soc. 83: 977-992.

Slingo A, Hodges KI, Robinson GR. 2004. Simulation of the diurnal cycle in a climate model and its evaluation using data from Meteosat 7. Q. J. R. Meteorol. Soc. 130: 1449-1467.

Soden BJ. 2000. The diurnal cycle of convection, clouds, and water vapor in the tropical upper troposphere. Geophys. Res. Lett. 27: 2173-2176.

Soden BJ, Wetherald RT, Stenchikov GL, Robock A. 2002. Global cooling after the eruption of Mount Pinatubo: a test of climate feedback by water vapor. Science 296: 727-730.

Stephens GL, CloudSat Science Team. 2002. A new dimension of space-based observations of clouds and precipitation. Bull. Am. Meteorol. Soc. 83: 1771-1790.

Trenberth KE, Guillemot CJ. 1998. Evaluation of the atmospheric moisture and hydrological cycle in the NCEP/NCAR reanalysis. Clim. Dyn. 14: 213-231.

Wentz FJ. 1997. A well-calibrated ocean algorithm for SSM/I. J. Geophys. Res. 102: 8703-8718.

Williams KD, Brooks ME. 2007. Initial tendencies of cloud regimes in the Met Office Unified Model. J. Climate (In press). 